\title{
Firearm Homicide-Suicides in North Carolina: Evidence from the North Carolina Violent Death Reporting System, 2004-2014
}

Rose Kerber

April 22, 2016

Advisor: Philip J. Cook, PhD. 
This project was completed in fulfillment of the requirement of the Masters of Public Policy Program at Duke University.

Data used in this project was provided by the North Carolina Violent Death Reporting System (NC-VDRS). I acknowledge the Office of the Chief Medical Examiner, the North Carolina State Center for Health Statistics, and Law Enforcement Agencies as the sources of NC-VDRS data.

Thank you to Scott Proescholdbell at NC-VDRS. 


\section{EXECUTIVE SUMMARY}

\section{Firearm Homicide-Suicides in North Carolina: Evidence from the North Carolina Violent Death Reporting System, 2004-2014}

Using data from the North Carolina Violent Death Reporting System, this analysis examines firearm homicide-suicides to discern patterns that differentiate homicide-suicides from other firearm homicides and suicides. Spanning the years 2004-2014 in North Carolina, this data set allows for three sets of logistic regressions that compare:

1) Homicide-suicide victims with other homicide victims, including sub-analyses of domestic homicide victims and intimate partner homicide victims

2) Homicide-suicide perpetrators with other homicide perpetrators, including a subanalysis of domestic homicide perpetrators

3) Homicide-suicide perpetrators with other suicidal individuals that committed suicide with a gun

These three avenues of inquiry allow for a complete picture of homicide-suicide victims and perpetrators, contributing to our understanding of the patterns behind these incidents. The major findings from this analysis are:

1) Almost all homicide-suicides were committed by men and involved the use of a gun. $95 \%$ of homicide-suicide perpetrators were male. $98 \%$ of homicide-suicides involved the use of a gun in at least one death, and $84 \%$ involved the exclusive use of a gun.

2) Female intimate partners, and spouses in particular, were the most frequent victims in homicide-suicides. Two thirds of homicide-suicides were intimate partner homicides. Women killed by their husbands in homicide-suicides outnumbered women killed by their husbands in simple homicides. Even when considering only intimate partner homicides, the odds that a female victim was murdered in a homicide-suicide were seven times higher than for males.

3) The termination of an abusive relationship is a major risk factor for homicidesuicide. Separation or divorce raised the odds that a killer committed suicide following a domestic homicide by 5 times.

4) More victims of homicide-suicides had restraining orders against their killers than other homicide victims. 55 homicide victims had restraining orders against their killers. Just over half of these victims died in a homicide-suicide. Among suicidal people, a restraining order raised the odds of committing homicide prior to suicide by four.

5) Mental illness and suicidal behavior are far less common in homicide-suicide perpetrators than in other suicidal individuals. $40 \%$ of solely suicidal people were suffering from Depression, compared to $9 \%$ of the homicide-suicide perpetrators. Those who committed homicide along with suicide were less likely to have left a note, expressed suicidal intentions or have made previous suicide attempts.

Homicide-suicides are a patterned type of violence that is distinct from other suicides and other homicides. The evidence presented in this analysis suggests that compared to both homicides and suicides, homicide-suicides are less reflective of personal problems experienced by the perpetrator and more reflective of troubled and abusive relationships between the perpetrator and the victim(s). The evidence suggests that perpetrators become maximally violent when they have lost control of a 
relationship. The intense fixation on the victim suggests that these incidents may be primarily homicidal. The suicidal act may be less premeditated than the homicide, and may instead reflect the perpetrator's complete loss of control and inability to function without their primary relationship.

Homicide-suicides are often preceded by a history of domestic violence and interaction with law enforcement. Interactions with law enforcement and the court system present key opportunities for intervention in abusive relationships that might prevent escalation. With better screening and robust policies that empower law enforcement and the court system to confiscate firearms from abusive individuals, hundreds of deaths could be prevented over the next decade.

Following policy examples from other states could strengthen North Carolina's capacity to prevent gun violence. North Carolina should adopt state laws that do the following:

1. Allow dating partners and all family members to petition for domestic violence restraining orders

2. Prohibit those convicted of misdemeanor stalking and all forms of domestic violence from firearm purchase or possession

3. Require removal of all firearms from the scene of domestic violence incidents

4. Require that law enforcement confiscate firearms from restraining order respondents and domestic violence misdemeanants

5. Adopt a system to screen for high risk domestic violence cases through coordination of the family court system, the mental health system, and law enforcement

6. Assign case managers to follow-up and report cases deemed high risk. 


\section{Introduction}

After 22 years of marriage, Jennifer Summers, 45, left her husband on May 25, 2015 (Sbraccia, 2015). In a violent outburst the night before, Michael Summers, 46, had slapped his wife across the face and pinned her to the ground as he stood on her chest (Jackson, 2015). Two days later Jennifer took out a restraining order against him, noting the presence of multiple firearms in their Clayton, NC home (WRAL, 2015). When Michael sued for custody of their two children nine days later, Jennifer withdrew the restraining order (Sbraccia, 2015). Over the months that followed, friends reported that the couple had reconciled (ABC11, 2015). On the night of November 23, 2015, their two sons, 11 and 16, went running for help to a neighbor's house as a vicious quarrel erupted between their parents. By the time police arrived at the scene, Michael had fatally shot Jennifer before turning the gun on himself (Jackson, 2015).

While rare, the distinctive pattern of violence that resulted in the Summers' deaths is not so uncommon as one might believe. Between 2004 and 2014, nearly 600 people died in homicidesuicides completed with a gun in North Carolina. These homicide-suicides accounted for less than $3 \%$ of the nearly 12,000 total gun deaths in North Carolina between 2004 and 2014. Of the gun deaths, there were 7,214 suicides, and 4,241 homicide victims. The remaining incidents were accidental gun deaths, legal intervention by law enforcement, or the circumstances were never established. Gun deaths in North Carolina over this time frame outnumbered violent deaths by all other methods combined, which numbered 9,112.

This analysis explores firearm homicide-suicides and provides answers to the following:

- How do the victims and perpetrators of homicide-suicides differ from the victims and perpetrators of simple homicides?

- How do the perpetrators of homicide-suicides differ from other suicidal individuals?

- What policy implications arise from developing answers to these questions?

The policy motivation for studying murder-suicides comes from a substantial body of literature that points to patterned — therefore predictable, and potentially preventable — behavior that results in homicide-suicides. Homicide-suicides often target females, usually intimate partners. Domestic violence precedes most homicide-suicides, and many victims have contact with law enforcement prior to their death. When a victim of abuse attempts to leave a relationship, they are in particular danger that is heightened when the perpetrator has access to a gun. This analysis contributes to the literature by comparing the individuals that commit firearm homicide-suicides to those who commit firearm homicides and firearm suicides, as well as comparing the victims of these crimes. This study is one of the first to examine homicide-suicides in the context of both other homicides and other suicides.

Mass shootings, the most visible incidents of gun violence in the US, can be considered a particular type of murder-suicide. Mass shootings often end with the suicide of the killer, and even when the killer does not commit suicide, he (rarely she) may reasonably expect to be killed during the event, and if he survives will never resume the life he led before the shooting. While there are too few incidents of mass shootings in North Carolina to do a robust quantitative analysis, some lessons from the study of murder-suicides may be more broadly applicable to mass shootings. The FBI defines a mass shooting as an incident that includes four or more homicides completed with a gun. Of the five events in North Carolina that meet that definition between 2004 and 2014, two were murder suicides. There were forty incidents over the same time period in which four or more people were shot in a single event. Five of these incidents ended with the suicide of the killer. 
Homicide-suicides that target family members or intimate partners are far more common than mass shootings that target acquaintances or strangers. However, many mass shootings begin with a domestic homicide ("Analysis of Mass shootings", 2015). There is substantial policy interest in addressing mass shootings, and insights from the study of more commonplace homicide-suicides could produce policy lessons that may help prevent multiple manifestations of interpersonal gun violence.

Homicide-suicides are a particularly enigmatic type of crime because it is difficult to discern whether these events are motivated primarily by a suicidal impulse, or the desire to kill others. This question is more than just a matter of semantics because there is abundant evidence that demonstrates fundamental differences between homicidal and suicidal people, including the influence of mental illness, impulsivity, and access to firearms. If murder-suicides are more like suicides due to mental illness and a history of suicidal behavior by the perpetrator, then attention toward mental health screening and access to behavioral health care ought to be policy priorities designed to prevent both suicides and the murders that may accompany them. If murder-suicides more closely resemble homicides, then they may be more effectively prevented through strengthening background check laws, domestic violence laws, enforcement of restraining orders, case management, and policing.

Using data from the North Carolina Violent Death Reporting System that documents all violent deaths in the state between 2004 and 2014, this analysis uses logistic regression to estimate odds ratios of suicide following homicide and homicide preceding suicide in firearm deaths. The evidence presented in this analysis suggests that compared to both homicides and suicides, homicide-suicides are less reflective of personal problems experienced by the perpetrator and more reflective of troubled and abusive relationships between the perpetrator and the victim(s). The evidence suggests that perpetrators become maximally violent when they have lost control of a relationship. The intense fixation on the victim suggests that these incidents may be primarily homicidal. The suicidal act may be less premeditated than the homicide, and may instead reflect the perpetrator's complete loss of control and inability to function without their primary relationship.

The appropriate policy recommendations that follow from the findings presented in this paper focus on identifying points of intervention in the breakdown of abusive relationships, when law enforcement may be well-positioned to prevent escalating violence. Improving the enforcement of existing federal and state laws would be a good start. Following policy examples from other states could strengthen North Carolina's capacity to prevent gun violence. North Carolina could consider adopting legislation that would:

7. Allow dating partners and all family members to petition for domestic violence restraining orders

8. Prohibit those convicted of misdemeanor stalking and all forms of domestic violence from firearm purchase or possession

9. Require removal of all firearms from the scene of domestic violence incidents

10. Require that law enforcement confiscate firearms from restraining order respondents and domestic violence misdemeanants

11. Adopt a system to screen for high risk domestic violence cases through coordination of the family court system, the mental health system, and law enforcement

12. Assign case managers to follow-up and report cases deemed high risk

This paper will begin with an overview of the relevant literature, move into a summary of the data and methodology employed in the analysis, and culminate in a discussion of the results and the insights gained. The paper concludes with a discussion of the policy implications that follow from the empirical analysis. 


\section{Review of the Literature}

The literature reviewed here establishes several key pieces of information relevant to homicide-suicide, mass shootings, and promising policy options for reducing firearm violence: 1) mass shootings often begin with a domestic homicide and end in the suicide or death of the shooter 2) access to firearms is a risk factor both suicide and homicide, particularly in domestic relationships 3) women are disproportionately victimized in domestic homicides and homicide-suicides, 4) homicide-suicides are frequently preceded by domestic violence and interactions with law enforcement or the court system, and 5) federal laws like the Lautenberg Amendment and state laws such as California's Gun Violence Restraining Order can be effective tools for reducing domestic homicides by keeping guns out of the hands of abusive individuals.

\section{Mass Shootings}

The existing literature on mass shootings focuses primarily on the individual pathology of the shooter. Overall, $88 \%$ of homicide-suicides are performed with a gun, $91 \%$ of the perpetrators are male, and $77 \%$ are white (Logan et al., 2008). School shootings have attracted particular attention, and a large body of research has sought to identify risk factors among school shooters. Studies have found that school shooters exhibit different behaviors than youth who are prone to other displays of aggression (Verlinden et al., 2000). A study on all forms of homicide and suicide in schools found that homicide perpetrators were nearly seven times more likely than homicide victims to have made a past suicide attempt (Anderson et al., 2001). Past suicide attempts and access to weapons are important risk factors for school shootings, along with history of substance abuse or violence, and a recent precipitating event like a major loss or humiliation (Preti, 2008). Bullying, social isolation, and failure to integrate into the school setting have also been identified as common traits among school shooters leading some researchers to conclude that vengeance is a primary motivation among school shooters. Suicidal intent, desire for vengeance, and access to firearms are risk factors that, when combined are particularly dangerous (Preti, 2008).

Mass shootings are a particular type of homicide-suicide that often intersect with the more common domestic homicide-suicide. A study of 133 mass shootings by Everytown for Gun Safety found that in $76(57 \%)$ of the cases, the shooter killed a family member or intimate partner in the course of their killing spree ("Analysis of Mass Shootings," 2015). This suggests that mass shootings may, in some cases be extensions of familial homicide-suicide. For the purposes of establishing mass shooting as an extension of other homicide-suicides, whether or not a shooter actually dies in the event may not be relevant if they might reasonably have expected to. According to an FBI report on active shooter incidents between 2000-2013, 94 out of 160 cases $(59 \%)$ ended in the death of the shooter. Sixty-four of those deaths were suicides_- $40 \%$ of the total number of incidents ("A Study of Active Shooter Incidents in the United States Between 2000 and 2013,” 2014). Sociologists Kalish and Kimmel (2010) suggest that consideration of social forces can help contextualize individual pathology and that entitlement and emasculation are closely linked with gender identity and desire for vengeance.

\section{Motive in homicide-suicides}

Vengeance appears to be a primary motivating factor in familial homicide-suicides and some suicides as well as in mass shootings. A qualitative study of adolescents who survived multiple suicide attempts found that vengeance was a commonly cited motive (Orri et al., 2014). Another study found that while fewer than $5 \%$ of homicides were followed by suicide, $59 \%$ of men who killed their female intimate partner with a firearm took their own lives immediately after (Barber et 
al., 2008). A study in England and Wales found similar figures for homicide-suicides, but found that in cases where men killed their families and themselves, the suicide was planned prior to the homicide (Milroy, 1998). Milroy suggests that these types of suicides are motivated by revenge rather than remorse. Vengeance may play a role in ordinary suicidal behavior, but plays a more central role in homicide-suicides.

Liem et al. (2009) conducted a study in the Netherlands that compared in-depth psychiatric reports on perpetrators of homicide-parasuicide (failed suicide), other perpetrators of domestic homicide, and other parasuicides. They found that compared to other perpetrators of domestic homicide, those who attempted suicide afterward were older, more likely to be male, more likely to be divorced, more likely to be depressed, and more likely to have killed multiple victims. Compared to other parasuicides, those who had committed homicide-parasuicide were equally likely to have made a prior suicide attempt, more likely to have a psychotic disorder or a personality disorder, and more likely to suggest that they were motivated by a relationship problem. Compared to both parasuicides and perpetrators of domestic homicide, the homicide-parasuicide group was more likely to have premeditated the crime, with the exception of intimate partner homicides (IPH). For the IPHs that were premeditated, the suicide attempt usually was not. Compared to other IPH perpetrators, those who attempted to kill themselves were more often motivated by a fear of abandonment and had a high level of emotional dependence on the victim (Liem and Roberts, 2009).

\section{Firearms and Femicide}

While men make up the vast majority of homicide victims, domestic homicides disproportionately target women. Femicide, the murder of women, is distinct from other forms of homicide because unlike in other homicides, femicide perpetrators are likely to be the spouse or intimate partner of the victim. Domestic violence and the attempted termination of the relationship by the victim are key risk factors specific to femicide, but not other homicides (Moracco et al., 1998).

A study of femicides in North Carolina between 1991 and 1993 found that half of all femicides were committed by a partner, and that young women and African American women were particularly at risk of femicide (Moracco et al., 1998). In addition, 44\% of the perpetrators had histories of assault, and 54\% of the femicides were committed with a gun. Women under age 55 and Caucasian women were particularly likely to have been killed with a gun. Two thirds of the femicide perpetrators had a history of domestic violence. The vast majority of femicide victims had been threatened and physically abused by their killer prior to the incident that resulted in their death. In more than half of the cases that noted a history of domestic violence, the victim had been in contact with law enforcement in the year before their death.

Femicide-suicides make up a majority of homicide-suicides. Marzuk et al. (1992) found that between half and three quarters of homicide-suicides involved a male murdering a female spouse or intimate partner before killing himself. In a study that compared victims of femicide-suicide to controls with a history of violent partner abuse, the factors that distinguished the femicide-suicide cases from other female victims of domestic violence included previous suicide threats by the perpetrator and a marital relationship between the victim and the perpetrator (Koziol-Mclain, 2006).

Campbell et al. (2003) found an increased risk of intimate partner femicide when the perpetrator had access to a gun, a stepchild in the home, stalking, rape and estrangement between the victim and perpetrator, especially if the victim was leaving for a new relationship. If the perpetrator had previously been arrested for domestic violence or had never cohabited with the victims, the risk of femicide decreased. A study of four field experiments in different US cities found that the deterrent effect of arrest on future domestic violence varied by marital status and 
employment, abusers who were married and employed were at a lower risk of re-offense than unmarried or unemployed perpetrators, for whom arrests actually increased the likelihood of reoffense (Berk et al., 1992). However, these effects varied by site and demographic composition of the population and the authors decline to make policy recommendations due to a lack of mechanistic clarity.

Studies across multiple countries have found that suicide follows homicide in about one in four cases of intimate partner femicide, compared to only one in twenty cases of non-partner homicides (Koziol-Mclain, 2006). Compared to other women in abusive relationships, women in abusive relationships where the abuser had access to a gun were at 25 times the risk of being killed in a femicide-suicide. At the household level, households with a gun and a history of domestic violence were at 20 times the risk of partner homicide compared to households with a history of domestic violence, but without the presence of a gun (Raissian, 2016).

\section{Firearms Access and Disqualifications}

Access to firearms is a key predictor of both homicide and suicide (Siegel et al., 2013; Miller et al., 2002). Keeping a gun in the house increases the odds of homicide within a household by 2.7 (Kellerman et al., 1993). More people in the US kill themselves with guns than with all other methods combined. Firearm availability actually increases the total number of suicides, rather than increasing only the proportion completed with a gun (Miller et al., 2002). There is little empirical support for the common misconception that people who intend to kill themselves will find a way to do it regardless of the available methods (Miller and Hemenway, 2008). For people who attempt suicide with a gun, the fatality rate is over $80 \%$ (Cook and Goss, 2014). In states with more gun control laws, suicide rates are lower than in states with fewer gun laws despite similar rates of suicide by other means, suggesting that suicide rates can be reduced through policies that limit access to guns (Brent, 2001).

According to the National Alliance on Mental Illness (2015), over 90\% of the people who commit suicide have been diagnosed with a mental illness. To purchase a gun through a federally licensed firearms dealer, an individual must be able to pass a background check conducted by the FBI through the National Instant Criminal Background Check System (NICS). An individual is barred from purchasing a firearm under several conditions, including two conditions relevant to mental health-involuntary hospitalization for a psychiatric condition, or having been "adjudicated as a mental defective" by a court or other legal authority. Depression is the most common mental illness among suicidal people, however depression is not a disqualifying factor for gun ownership, nor is it likely to get someone involuntarily committed to a mental institution, which is a disqualifying factor (Swanson et al., 2013). "In other words, people suffering from the one mental health condition that is most closely and frequently linked to suicidality are unlikely to show up in a background check" (Swanson et al., 2013, p. 50). Swanson et al found that between 2007-2009 after

Connecticut improved NICS reporting, violent crime was effectively reduced among the $6.2 \%$ of the population with mental health disqualifiers, however $96 \%$ of the violent crimes during that period were committed by people without a mental health disqualifying record.

State adherence to mental health reporting requirements varies widely. Even for the small percentage of the mentally ill population that meet either criteria, states have historically failed to report many cases to the FBI, meaning that individuals who should legally be prevented from purchasing a firearm could pass a background check in a state with lax reporting (Law Center to Prevent Gun Violence, 2013). Unfortunately, even with proper reporting, only a few individuals who have carried out a mass shooting would have failed a background check on these criteria (Buchanan et al., 2015). The shooter at Virginia Tech in 2007 is one exception. He had been involuntarily committed to a mental institution and should not have passed a background check, but did (Law 
Center to Prevent Gun Violence, 2013). In the wake of the Virginia Tech shooting, the NICS Improvement Amendments Act of 2007 began to incentivize states to improve mental health records reporting to the National Instant Criminal Background Check System (NICS) (Bureau of Justice Statistics, 2015). About half the states have enacted enabling legislation to be eligible for grants to assist with mental health records reporting under NIAA, and the number of mental health records now in NICS has increased sevenfold since 2007 (Law Center to Prevent Gun Violence, 2013).

In 1994, the Violent Crime Control Act made it illegal for anyone to possess or purchase a firearm while subject to a restraining order that protects a spouse, former spouse, cohabitating partner or the child of an intimate partner (Vigdor and Mercy, 2006). Under the 1996 expansion of the Gun Control Act, people with a misdemeanor conviction for domestic violence are also prohibited from owning or purchasing a gun. This policy, known as the Lautenberg Amendment, expanded the existing law to prohibit domestic violence misdemeanants from gun possession or purchase. Many perpetrators of domestic violence ultimately plead guilty to a misdemeanor rather than a felony charge- thus the felon firearm prohibition in the 1968 Gun Control Act was ineffective at keeping guns out of the hands of domestic abusers. The Lautenberg Amendment requires that people convicted of misdemeanor domestic violence sign a statement swearing that if they are found in possession of a firearm, they may face federal prosecution. Many states have legislation that requires more than a sworn statement to demonstrate adherence to the Lautenberg Amendment.

\section{Domestic Violence, Restraining Orders, and Firearms}

While federal law requires that abusers convicted of a misdemeanor domestic violence be notified and given a hearing before the firearm prohibition goes into effect, some states have additional laws to prevent domestic violence misdemeanants and restraining order respondents from obtaining access to guns. Some states disqualify more categories of misdemeanant from gun possession than just those prohibited under federal law. For example, Illinois also disqualifies those convicted of misdemeanor stalking or who have violated a restraining order (Vigdor and Mercy, 2006). Some states empower law enforcement to confiscate weapons or issue ex parte protective orders, also known as temporary restraining orders. While federal law only recognizes restraining order petitions for the protection of intimate partners or children, several states use a more expansive definition of 'intimate partner' and grant restraining orders to dating partners, former dating partners, and other family members of an abusive individual.

One study of re-abuse among female restraining order petitioners found substantial declines in reports of abuse after a restraining order had been issued, although low socioeconomic status and the presence of children increased the odds of re-abuse (Carlson et al., 1999). Abusers who share children with their victim often use the family court system to perpetuate abuse through prolonged custody disputes that serve to maintain contact between victim and abuser (Przekop 2011). Even when victims have restraining orders or move away, custody battles will force them into contact with their abusers. LeFevre-Sillito and Salari (2011) found that children were more likely to witness a homicide-suicide than to be either absent or killed in the incident. Using news coverage, police reports and other incident descriptions, they classified individual perpetrators as primarily suicidal (indicated by previous suicide attempts, a suicide note, financial problems, poor health, depression and no history of domestic violence) or primarily homicidal (indicated by a history of domestic violence, stalking, restraining orders, crimes against primary victim, and seeking the victim out at his/her residence). They found that children killed in homicide-suicides were typically not the 'primary' victims and were more likely to be killed if the perpetrator was primarily suicidal. 90\% of children killed in a homicide-suicide were the biological children of the perpetrator. 
There is compelling evidence that state and federal domestic violence gun prohibitions reduce domestic homicides. One study of the effect of the Lautenberg Amendment on domestic homicides found a $17 \%$ reduction in female partner homicides and a $25 \%$ reduction in domestic child homicides (Raissian, 2016). Another study found that additional state level laws on misdemeanor domestic violence gun prohibition did not lead to any reduction in IPH beyond the effect of federal law, but that additional state level restraining order gun prohibitions reduced IPH by $8 \%$ (Vigdor and Mercy, 2006). However, restraining orders are not foolproof. Guns were the primary weapons used by IPH perpetrators against whom the victim had a restraining order (Sillito and Salari, 2011). However, Raissian (2016) and Vigdor and Mercy (2006) provide compelling evidence that restraining order prohibitions and federal misdemeanant prohibitions do reduce domestic homicides despite the major limitations of state and federal gun laws. Most states have no mechanism to confiscate existing firearms from abusers, and background check requirements can be circumvented easily in most states. While it is difficult to estimate how many gun sales are conducted without a background check, the most frequently cited estimate is about 40\% (Cook and Ludwig, 1996).

States that issue ex parte restraining orders prohibit firearms purchase and possession before the abusive individual is notified and has a hearing. North Carolina is one of thirteen states that allows for ex parte orders (N.C.G. S. \50B-1, 50B-3(11), 50B-3.1). Women who leave an abusive relationship are $75 \%$ more likely to be severely injured or killed by their abuser than women who remain in abusive relationships (Przekop, 2011). Ex parte orders may be especially important for reducing IPH because many women seek restraining orders while separating from an abuser, during which they are at a heightened risk of homicide (Zeoli and Frattaroli, 2013).

Policy Models for Preventing Gun Violence

Sixteen states require the surrender of firearms by those convicted of domestic violence misdemeanors, via law enforcement confiscation (NJ, MA, HI) or through a court order. California law allows courts to issue search warrants for abusers who do not give up their weapons (Law Center to Prevent Gun Violence, 2015). California has among the strictest gun laws in the country, including a provision that requires all gun sales go through a licensed dealer who conducts an FBI background check. In other states, private gun sales and gun show sales are not subject to the background check requirement (Law Center to Prevent Gun Violence, 2015). California has attempted to close this so-called loophole by requiring private sales and gun show sales to be certified by a state-licensed dealer who is obligated to perform a background check. California also has a 10-day waiting period for new gun owners. A federal appeals court ruled in 2015 that the 10day waiting period does not apply to people who already own guns. The ruling judge reasoned that a cooling off period would not prevent impulsive acts of violence for individuals who already had access to firearms (KRCA, 2015). California also has a new Gun Violence Restraining Order (GVRO). This law, passed in 2014, allows people to report dangerous behaviors in others so that a court can decide to remove firearms from a person posing an imminent threat to themself or others (Horwitz et al., 2015; Frattaroli et al., 2015). Furthermore, California has had success in training law enforcement to recover firearms from restraining order respondents (Wintemute et al., 2014). Between 2006 and 2014, California confiscated 10,000 guns from legal purchasers who later became prohibited from possession.

There are a variety of policy options for states seeking to reduce domestic gun violence.

North Carolina could follow the lead of states like California that actively confiscate weapons from abusive individuals. These measures have the potential to prevent thousands of violent deaths. Zeoli and Frattaroli (2013) provide a variety of federal policies that could reduce domestic gun violence; require federal background checks on all gun sales, create incentives for states to automate 
restraining order and domestic violence misdemeanor reporting to NICS, create incentives for states to create gun registries, allow current and former dating partners to secure restraining orders, extend lifetime gun prohibitions to those convicted of misdemeanor stalking and those who have violated restraining orders, and provide training and technical assistance to improve implementation at the state level. States can pursue any of these options independently of federal progress toward these goals. Logan et al. (2008) emphasize the importance of integrating court systems with the mental health system to identify family court cases that are especially likely to become violent. In particular, they suggest that case managers could evaluate domestic violence history and firearm access and provide referrals to mental health services.

\section{Data and Methodology}

This project was conducted with Institutional Review Board approval from Duke University in accordance with a Data Use Agreement with North Carolina's Violent Death Reporting System (NC-VDRS). North Carolina is one of 32 states that report comprehensive data on violent deaths to the CDC's National Violent Death Reporting System (NVDRS). NVDRS collects comprehensive information from death certificates, coroner and medical examiner reports, law enforcement reports and crime labs on a variety of facts relevant to violent deaths including mental health issues, interpersonal relationships, toxicology, and other crimes related to a particular incident (CDC, 2015)

Data from NC-VDRS was disaggregated by incidents, suspects, and victims. Perpetrators of homicide-suicide appeared in both the victim and suspect file, and were identifiable in the suspect file by having both attempted suicide and being labeled as "both suspect and victim". Certain nonsuicidal homicide suspects who had been killed in the event of killing someone else also appeared as "both suspect and victim". Perpetrators of homicide-suicide were also identifiable in the victim folder with a label of "both victim and suspect" if their death manner was suicide. The homicide victims of homicide-suicide were identifiable by an Incident ID number that could be matched to the perpetrator. All incidents were verified as cases of homicide-suicide by cross-referencing cases with the detailed narratives provided in the incident file from law enforcement officers and medical examiners

The analysis progressed in three stages. The first stage consisted of logistic regressions comparing homicide victims in homicide-suicides to other homicide victims, with a particular focus on other victims of domestic homicide. This set of regressions was important for establishing the likelihood of having died in a homicide-suicide based on the victim's relationship to the killer. Models have been reported separately for all homicide victims, domestic homicide victims, and intimate partner homicide victims. Domestic and intimate partner homicides were designated based on the relationship of the victim to the killer. Domestic homicides include spouses, current intimate partners, children, parents, and other family members of the killer. Intimate partner homicides include spouses, current intimate partners, and former intimate partners of the killer.

The second set of logistic regressions compared perpetrators of homicide-suicide to other perpetrators of homicide. The third stage of analysis compared perpetrators of homicide-suicide to other suicidal individuals. These regressions included mental health indicators, previous suicidal behavior, and a range of precipitating circumstances that were not available for either homicide victims or homicide perpetrators. 


\section{Results and Discussion}

Between 2004 and 2014 in North Carolina, there were 3,509 firearm homicides, including 258 homicide-suicides. Two thirds of homicide-suicides were intimate partner homicides. In fact, more spouses that were killed with a gun died in homicide-suicides than in simple cases of homicide during this time period. In other words, more than half of spousal homicides were homicidesuicides. In all, $17 \%$ of all homicides were domestic homicides - the killer targeted their spouse or current partner, child, parent, sibling, or other family member. One third of domestic homicides ended in the suicide of the perpetrator.

Most homicidal gun violence claimed only one life, but 198 incidents included multiple homicide victims (Table 1). About $5 \%$ of homicides targeted multiple victims, compared to $11 \%$ of murder-suicides. In $12 \%$ of homicides, at least one victim survived, while only $8 \%$ of homicidesuicides left survivors. Homicide-suicides are especially deadly, not only because the death of the killer increases the fatality rate, but also because they claim more innocent lives per incident and are less likely to leave survivors (Table 2).

Table 1

\begin{tabular}{|c|c|c|}
\hline \multicolumn{3}{|c|}{ Total Number of Homicide Victims by Incident Type } \\
\hline $\begin{array}{c}\text { Number of Homicide } \\
\text { Victims }\end{array}$ & Homicides & Homicide-suicides \\
\hline 1 & 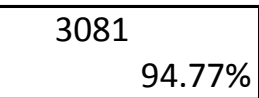 & $\begin{array}{l}230 \\
89.15 \%\end{array}$ \\
\hline 2 & 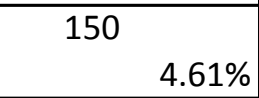 & 20 \\
\hline 3 & 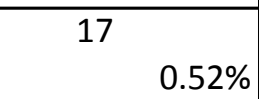 & $2.33 \%$ \\
\hline 4 & 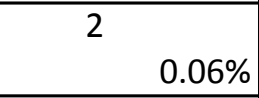 & $0.39 \%$ \\
\hline 5 & $0.00 \%$ & $0.39 \%$ \\
\hline 6 & $0.00 \%$ & $0.00 \%$ \\
\hline 7 & $0.00 \%$ & $0.00 \%$ \\
\hline 8 & 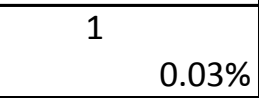 & $0.00 \%$ \\
\hline Total Homicide Victims & 3448 & 297 \\
\hline Total Incidents & 3251 & 258 \\
\hline Victims:Incident & 1.06 & 1.15 \\
\hline
\end{tabular}


Table 2

\begin{tabular}{|c|c|c|}
\hline \multicolumn{3}{|c|}{ Total Number of Non-fatal Injuries by Incident Type } \\
\hline Number Injured & Homicide & Homicide-suicide \\
\hline 1 & $\begin{array}{ll}285 & \\
& 8.77 \%\end{array}$ & 15 \\
\hline 2 & $\begin{array}{ll}67 & \\
& 2.06 \%\end{array}$ & $1.94 \%$ \\
\hline 3 & $\begin{array}{ll}14 & \\
& 0.43 \%\end{array}$ & $0.00 \%$ \\
\hline 4 & $0.15 \%$ & $0.00 \%$ \\
\hline 5 & $0.03 \%$ & $0.00 \%$ \\
\hline Total Non-fatal Injuries & 372 & 20 \\
\hline $\begin{array}{l}\text { Percent of Incidents with } \\
\text { Nonfatal Injuries }\end{array}$ & $11.44 \%$ & $7.75 \%$ \\
\hline
\end{tabular}

Between 2004 and 2014, 274 murder-suicides claimed the lives of 582 North Carolinians. Of those 274 events, 270 involved the use of a gun in at least one death and 230 were completed exclusively with a gun. More than one weapon was used in 39 incidents (Table 3). In 11 of the mixed-method incidents, the victims were killed with a gun and the perpetrators committed suicide by another method. In the remaining 28 incidents, the victims died by another method, and the killers committed suicide with a gun. In 258 total incidents, the killer used a gun to complete suicide following homicide.

Table 3

\begin{tabular}{|c|c|c|}
\hline \multicolumn{3}{|c|}{ Homicide Suicides in North Carolina, 2004-2014 } \\
\hline Weapon & Total Incidents & Total deaths \\
\hline All & 274 & 582 \\
\hline Only gun & 230 & $84.2 \%$ \\
\hline Gun + Other weapon & 39 & $14.4 \%$ \\
\hline No guns & $1.5 \%$ & $1.4 \%$ \\
\hline
\end{tabular}

\section{A. Comparing victims of firearm homicide to firearm homicide-suicide victims}

The most obvious difference-and one that is well established in the literature-between firearm homicide victims and firearm homicide-suicide victims is that the homicide victims in homicide-suicides are overwhelmingly female (Figure 1). Homicide-suicide victims are also very likely to have been married to, or in a current or former intimate relationship with, their killer (Figure 2). 
Figure 1

Female gun deaths

North Carolina, 2004-2014

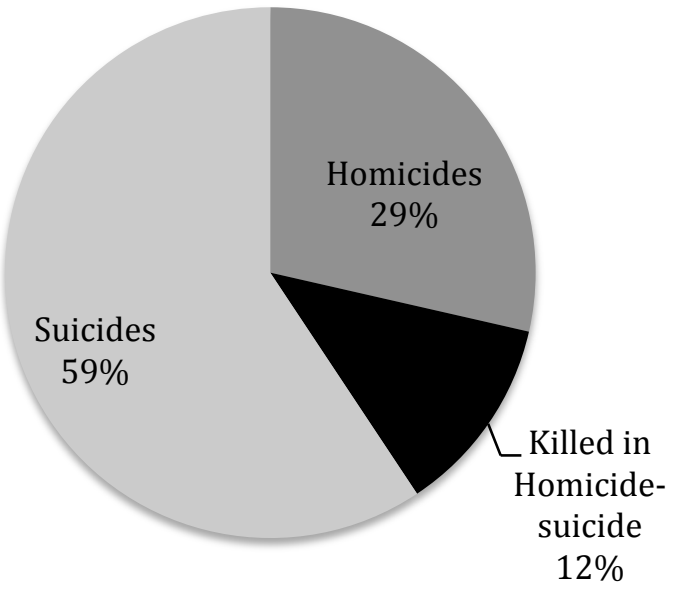

Male gun deaths

North Carolina, 2004-2014

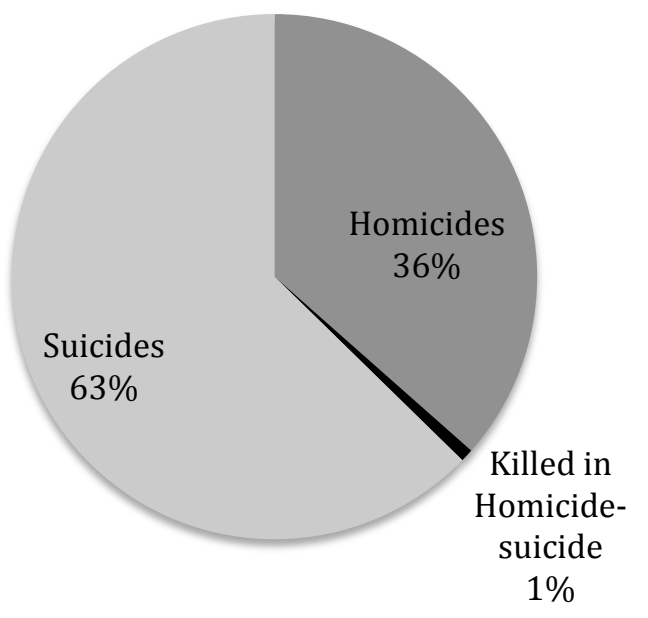

Figure 2

\section{Intimate Partner Homicides and Homicide- Suicides,}

Gun deaths in North Carolina, 2004-2014

- Spouse $\square$ Partner Ex

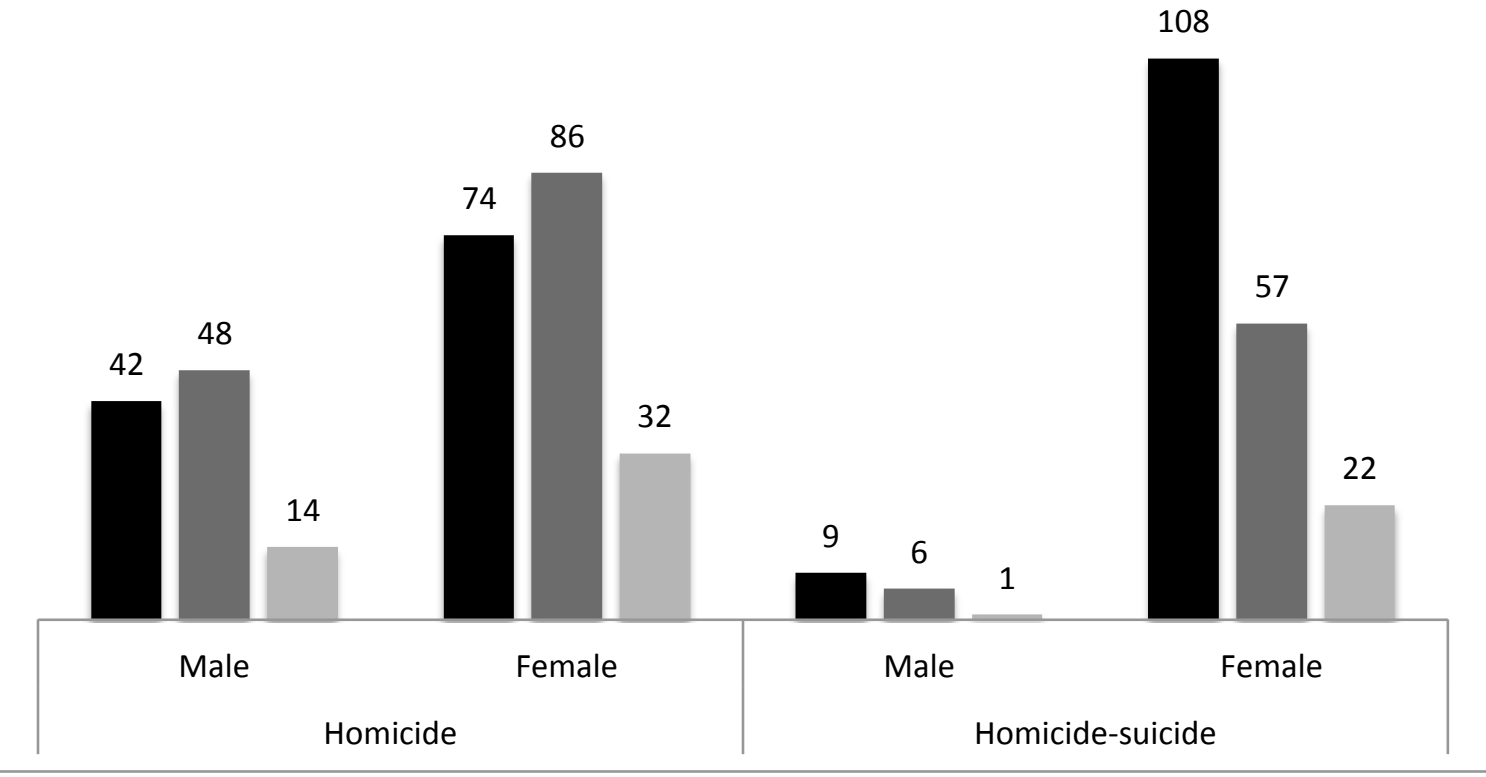


More spouses were killed in homicide-suicides than in simple firearm homicides in North Carolina over a ten-year period. While two in three spouses murdered in a single firearm homicide were female, over nine in ten spouses murdered in a firearm homicide-suicide were female. Fiftyone wives killed their husband. Only $20 \%$ of wives who killed their husband went on to kill themselves, compared to $60 \%$ of husbands who killed their wife. Murdered wives outnumber murdered husbands by less than two to one in cases of simple homicide, but by twelve to one among those murdered in a homicide-suicide. Half of all firearm femicides were intimate partner homicides - the victim was the current or former wife or girlfriend of the killer.

The male-female pattern is similar for non-marital intimate partners, and for former partners and spouses. While over half of murdered spouses were killed in a homicide-suicide, one third of murdered exes and non-marital intimate partners were killed in homicide-suicides. Female intimate partners outnumber male intimate partners killed in simple homicide by less than two to one, but nearly ten to one in cases of homicide-suicide. Female exes outnumber male exes in cases of simple homicide by just over two one, and by 22 to one in murder-suicides.

Half as many daughters or stepdaughters were murdered by a parent or stepparent as sons or stepsons. However, two-thirds of the female children who were killed by a parent or stepparent died in a murder-suicide, compared to fewer than half of male children killed by a parent or stepparent. Unlike intimate partners and children, the vast majority of murdered parents, siblings, and other family members died in simple homicides, rather than in homicide-suicides $(86 \%, 98 \%$, and $95 \%$, respectively).

Male victims outnumber female victims in cases of simple homicide in all but three relationship categories - spouses, non-marital intimate partners, and former spouses or partners. However, in cases of homicide-suicide, female victims also outnumber male victims among murdered children, parents, and strangers, as well as the three intimate partner categories. Even among domestic homicides - defined here according to relationship, including spouses, current intimate partners, children, parents, siblings, and other family members - there are notable differences between the victims of homicide and homicide-suicide. Spousal victims, intimate partners, and children make up larger percentages of homicide-suicides than single homicides. Siblings, parents, and other family members make up relatively larger proportions of homicide victims than homicide-suicide victims (Figure 3). 
Figure 3

\title{
Domestic Homicide and Domestic Homicide- suicide victims by Relationship to Killer
}

\author{
Gun deaths in North Carolina, 2004-2014
}

Domestic homicide victims Domestic homicide-suicide victims

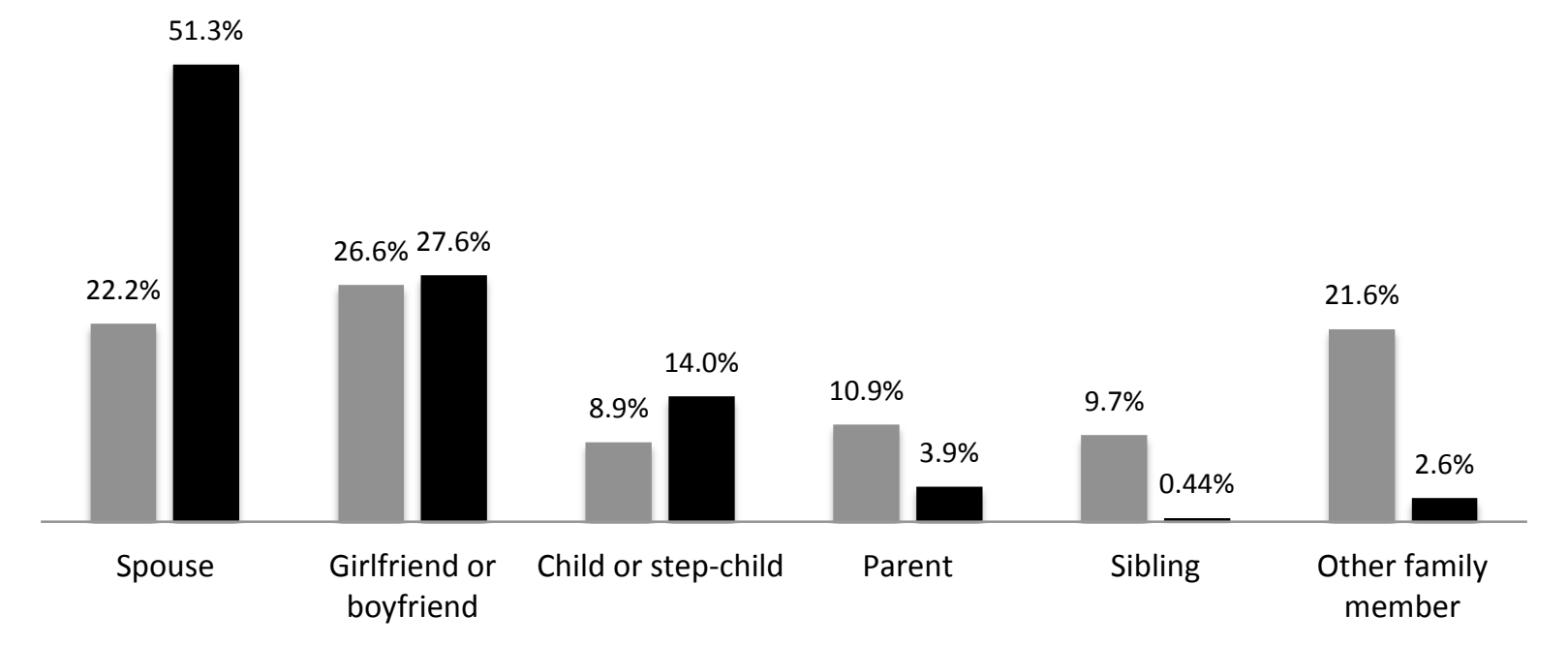

The precipitating circumstances show some differences for homicide victims and homicidesuicide victims. Proportionally fewer homicide-suicide victims were involved in an argument at the time of death, involved in another crime at the time of death, were using drugs, or fought back against their killer. Limiting the scope to domestic homicides, the same patterns hold for all circumstances. Three quarters of homicide-suicide victims were noted as having had a violent partner, compared to one in ten homicide victims. However, for victims that were killed by a partner, partner violence is self-evident and these statistics may not give an accurate depiction of pre-homicide partner violence between these two groups.

Looking at Table 4, which presents odds ratios of homicide victims having died in homicidesuicide compared to simple homicide, we can isolate several risk factors for homicide-suicide. Model 3, which accounts for relationships between all murder victims and their killers, shows that females were at five times the odds of males of being killed in a homicide-suicide rather than a homicide. Being white and having a military background each increase the odds of victimization in homicidesuicide over homicide by about 2.3 times relative to other races and civilians, respectively. Being under the age of 21 increased the odds of homicide-suicide over homicide by $65 \%$. Involvement in another crime and fighting back against the killer reduced the odds of homicide-suicide by $61 \%$ and $80 \%$, respectively. 


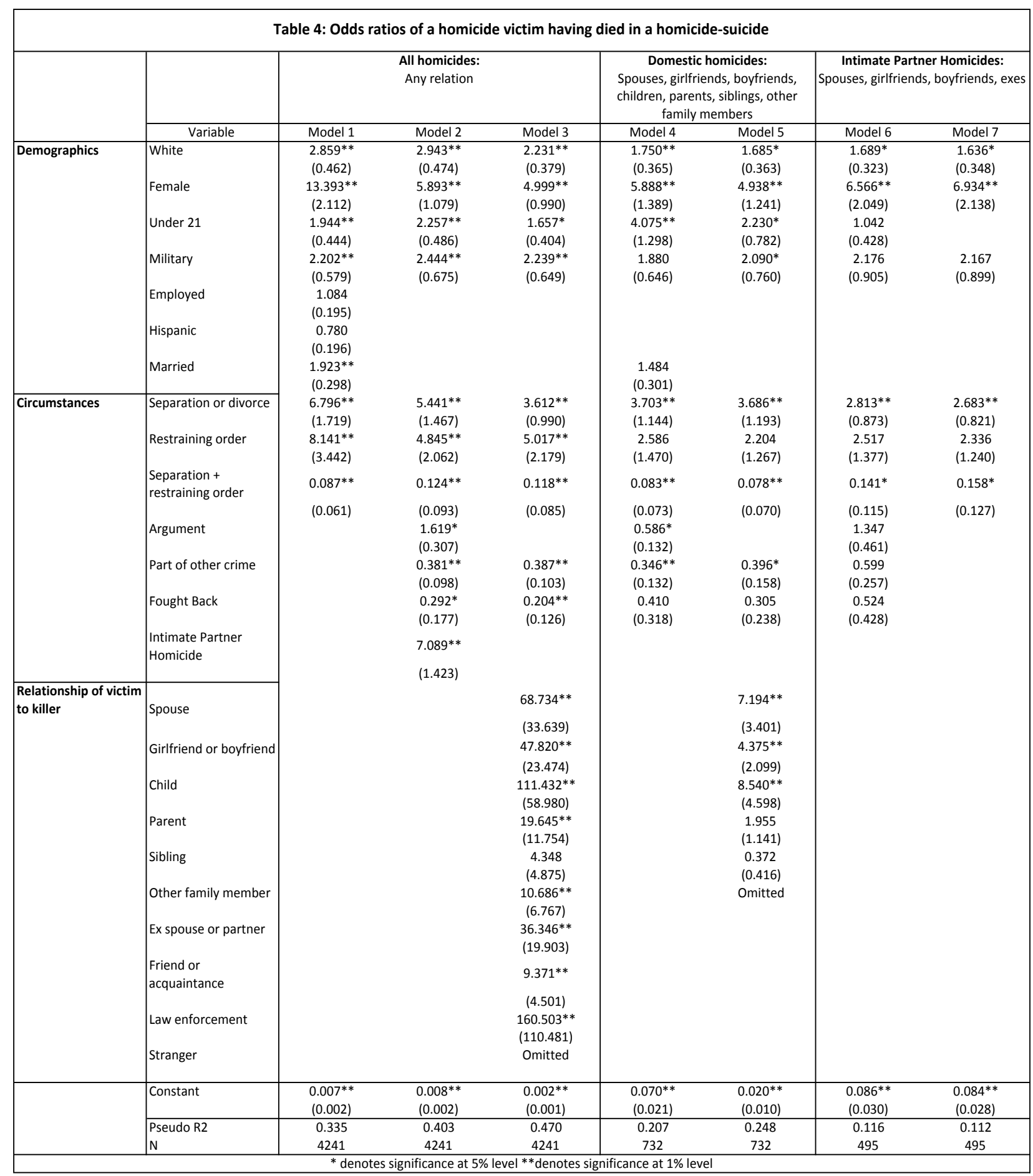

In Model 2, we see that if the homicide victim was a current or former intimate partner of their killer, the odds that the incident ended with the killer's suicide were seven times higher.

Looking back to Model 3, if the victim had initiated divorce, separation, or was in the process of breaking up with the killer, the odds of being killed in a homicide-suicide rather than a homicide more than tripled. Importantly, if the victim had ever taken out a restraining order or any type of order of protection against the killer, the odds of having died in a homicide-suicide rather than a homicide were 5 times higher. However, the combined effect of a current separation and a 
restraining order also had a significant effect. Multiplying the odds ratios for separation and a restraining order by the odds ratio for the interaction yields a combined effect of 2.138, meaning that victims who had both a restraining order and were separating from the killer were over two times as likely to have died in a homicide-suicide than in a homicide, but less likely than either the separation without restraint or restraint without separation groups to have died in a homicidesuicide.

While these are significant factors in determining whether an act of fatal violence ends with homicide or culminates in the killer's suicide, these results do not directly tell us anything about the efficacy of restraining orders, since the entire sample died of homicide (although that fact alone indicates there is substantial room for improvement in their enforcement). However, these results indicate that the particular type of violence leading to a homicide-suicide may either be more likely to cause a victim to request a restraining order against an abusive partner, or that the presence of a restraining order is more likely to inspire suicidal behavior in the killer than in other homicides. In the former scenario, victims may be well equipped to recognize an escalating pattern of abuse that is more characteristic of homicide-suicide than homicide. If so, their interactions with law enforcement and the court system are key opportunities for intervention.

Both separation and restraining orders are far more common in incidents of homicidesuicide than in incidents of either homicide or suicide (Figure 4). One in five homicide-suicides involves a current separation, break-up, or divorce, compared to fewer than one in ten suicides and just over one in one-hundred homicides. Restraining orders are quite rare in instances of homicide and suicide, but are present in $7 \%$ of homicide-suicides. Roughly half of the victims who initiated a restraining order were currently separating from their abuser at the time of their death.

Even among the victims of intimate partner homicides, proportionally more victims of homicidesuicide had initiated a restraining order against their partner (Figure 5). Of the IPH homicide-suicide victims, nearly one in four was separating from their abuser, compared to one in ten of the other IPH victims. About 3\% of each group had initiated both separation and had petitioned for a restraining order.

\section{Figure 4}

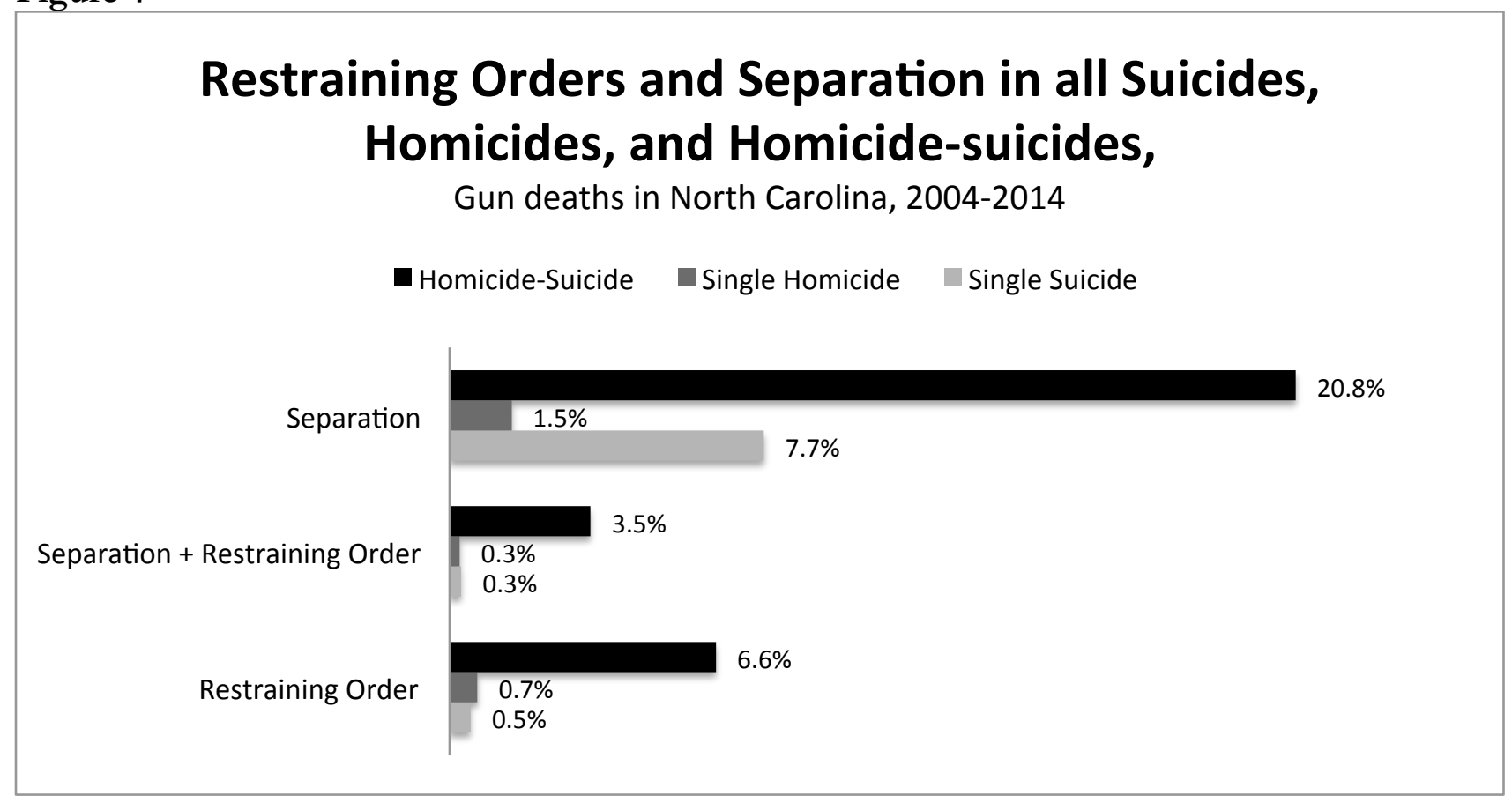


Figure 5

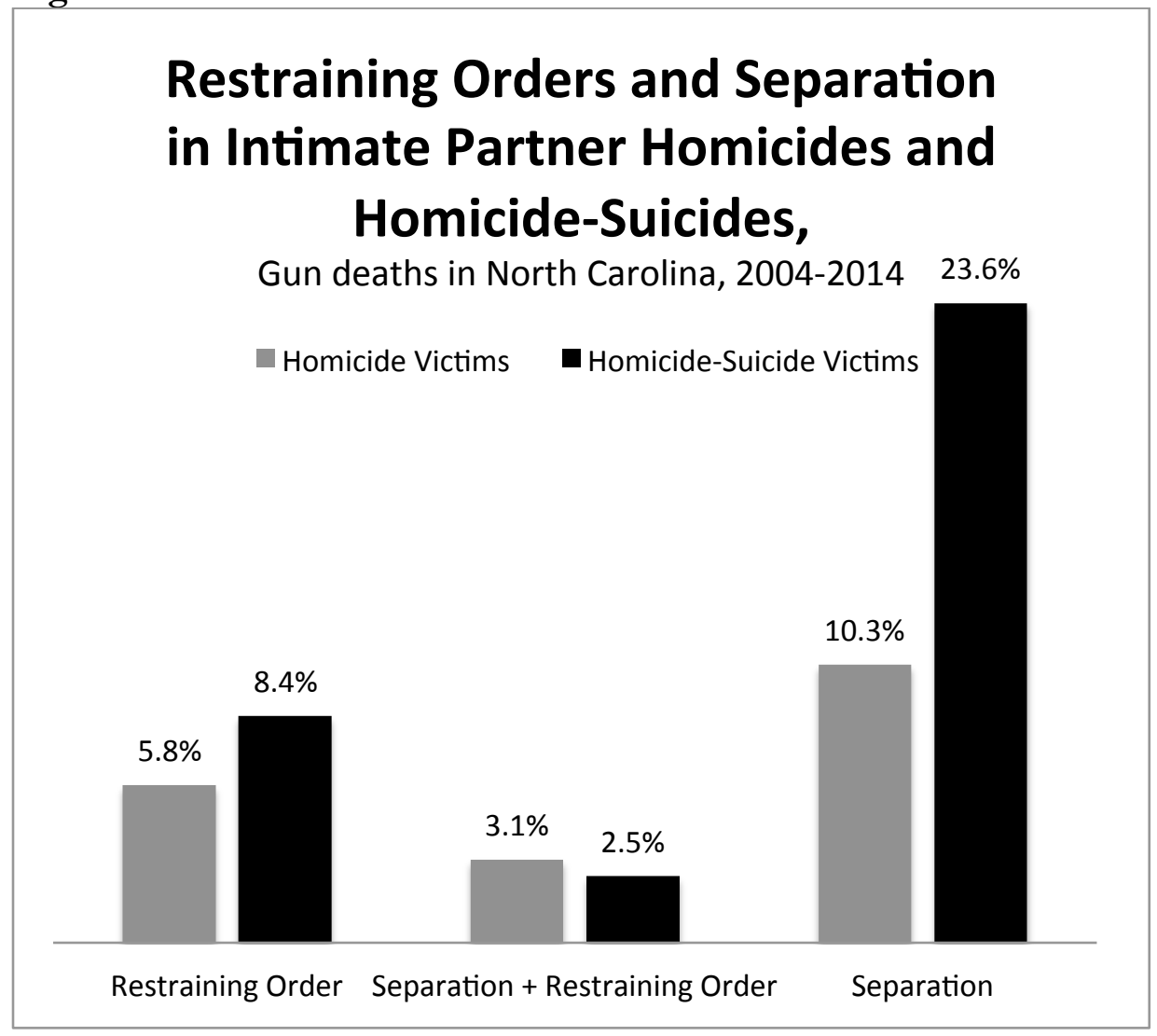

Table 4, Models 6 and 7 provide odds ratios for IPH victims having died in a homicidesuicide rather than a homicide. Even when the analysis is limited to IPH, a few factors are still significant in differentiating homicide-suicide victims from homicide victims. First, females had seven times the odds of males of being victims of homicide-suicide compared to other IPH victims. One might expect that because the vast majority of IPH victims are female, the effect of being female would cease to be important when comparing homicide-suicide victims to homicide victims. However, the victim being female seems to have a strong effect on the likelihood of suicide following homicide, even when the sample is restricted only to IPH victims. Next, separation continues to be a strong predictor of homicide-suicide, but having a restraining order ceases to be significantly predictive of homicide-suicide, although the interaction remains significant. However, multiplying the interaction by the odds ratios of separation and having a restraining order produces an odds ratio for the interaction of 0.99 , predicting approximately equal odds of homicide and homicide-suicide.

\section{B. Comparing homicide-suicide perpetrators to other perpetrators of firearm homicides}

Restraining order and separation frequency among firearm homicide perpetrators mirrors the frequency of these events among victims. Comparing perpetrators of firearm homicide and firearm homicide-suicide offers other insights, however. Of over 3,500 identified homicide suspects in North Carolina gun deaths between 2004 and 2014, 285 perpetrators were suicidal. Of the suicidal individuals, 258 succeeded in the suicide attempt, and 27 attempted an incomplete suicide. Because 
these individuals made a suicide attempt with a gun, which is especially likely to be fatal, these efforts can reasonably be considered to have been earnest attempts at suicide and therefore can be considered alongside the cases of completed suicides in certain analyses. However, there are some important differences between the successful and unsuccessful suicide groups. Among the unsuccessful suicides, none were separating from their partners and only five killed a family member. Based on the successful suicide group, we would have expected that about five were separating, and that about 22 would have killed a family member. Also, women make up $15 \%$ of the failed suicide attempts following homicide, compared to just over $5 \%$ of the successful suicides. There were also proportionally more cases of mental illness among the failed suicides, but there were so few cases of documented mental illness in the entire sample that this may be purely by chance.

Compared to other homicide suspects, a larger proportion of the suicidal homicide perpetrators were male, white, and Hispanic (Figure 6).

In about $30 \%$ of domestic homicides, the killer attempted suicide afterward. Three quarters of suicide attempts among homicide perpetrators followed a domestic homicide. Domestic homicide perpetrators are more likely to have been apprehended or known to law enforcement than perpetrators in an extra-familial homicide. As with domestic homicide victims, domestic homicide perpetrators are a good comparison group for domestic homicide-suicide perpetrators because most homicide-suicides are domestic. Another advantage of a comparison with other domestic homicides is that there is more complete data on the identity of the suspects involved than in other homicides. Models 3 and 6 in Table 1 have been limited to domestic homicide perpetrators.

Figure 6

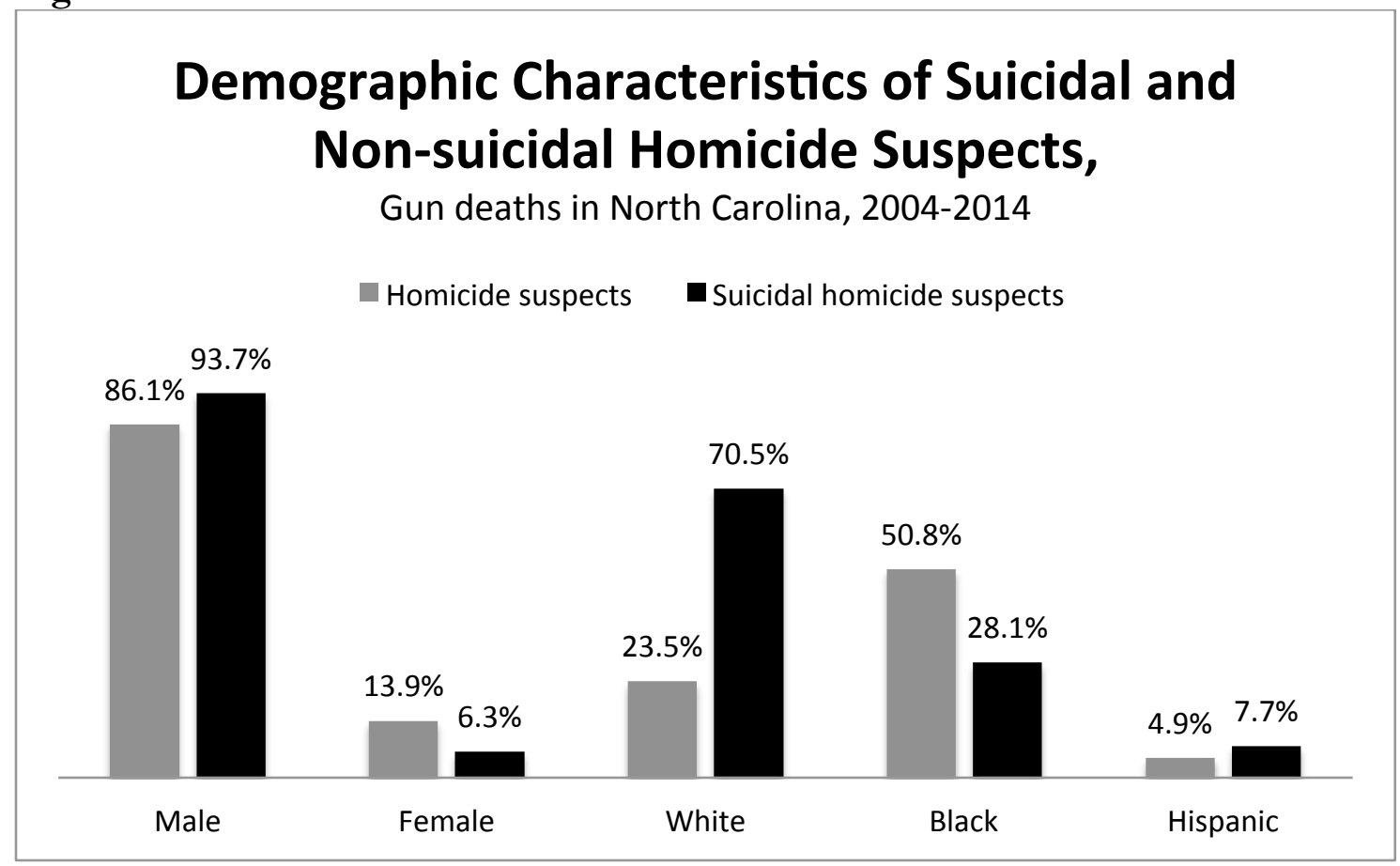

In about $15 \%$ of both homicides and homicide-suicides, more than one victim other than the perpetrator was killed. Larger proportions of homicide-suicide perpetrators had an abuse history, were caregivers, had a documented mental illness, were separating from their partner, had a restraining order, a history of domestic violence, or were involved in a custody battle (Figure 7). Abuse history and domestic violence capture similar behavior. Abuse history had been recorded by NC-VDRS and was included in the initial data set. Domestic violence captures incidents with 
descriptions that specifically included the terms "domestic violence" or "domestic abuse" and largely includes incidents known to law enforcement prior to the homicidal incident.

Figure 7

\section{Relationship Characteristics of Suicidal and Non-suicidal Homicide Perpetrators,}

Gun deaths in North Carolina, 2004-2014

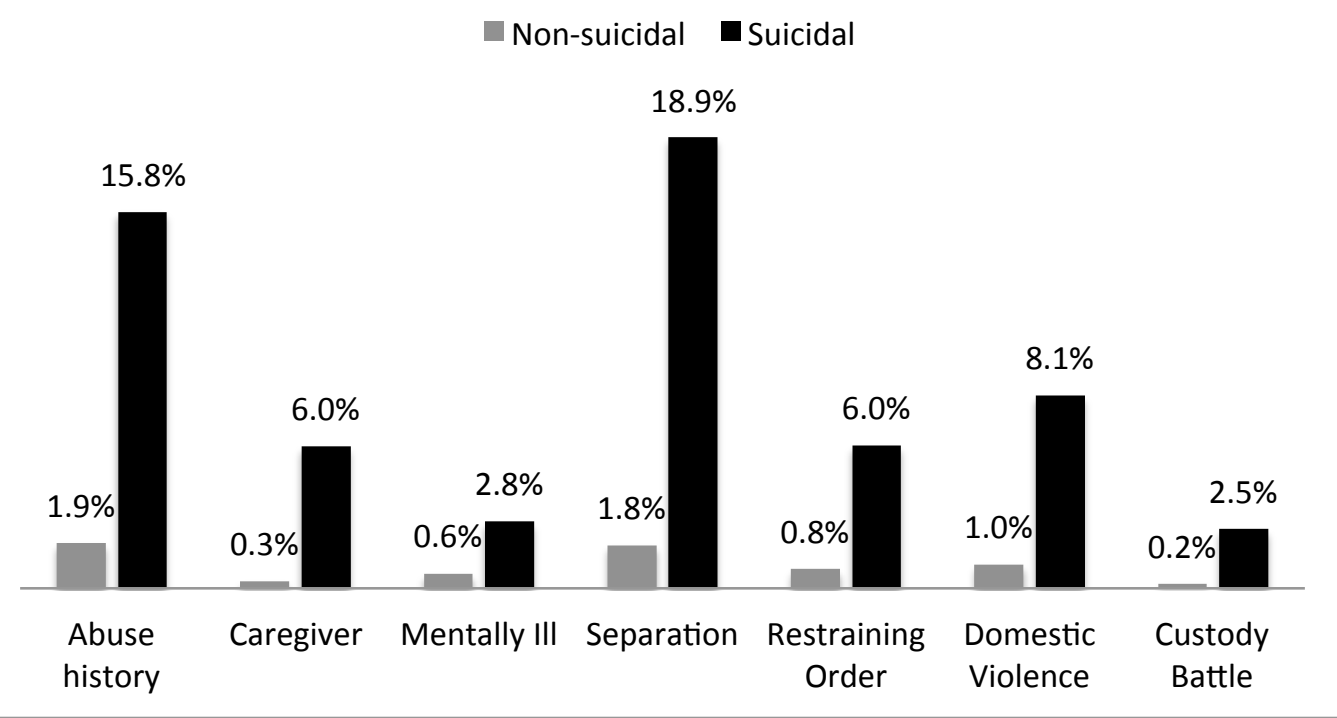

Table 5, Model 2 presents odds ratios that a person who perpetrated a homicide successfully committed suicide. Killers who were white had eight times the odds of committing suicide as nonwhite killers, and male killers had four times the odds of committing suicide as female killers.

Neither being Hispanic nor having a mental health problem had a significant effect. It seems likely that mental health problems have been underreported for homicide suspects, given that only 28 of 3,500 (less than 1\%) individuals had a recorded mental illness, when overall rates of mental illness are estimated to be as high as $20 \%$ among the general population (NAMI). 


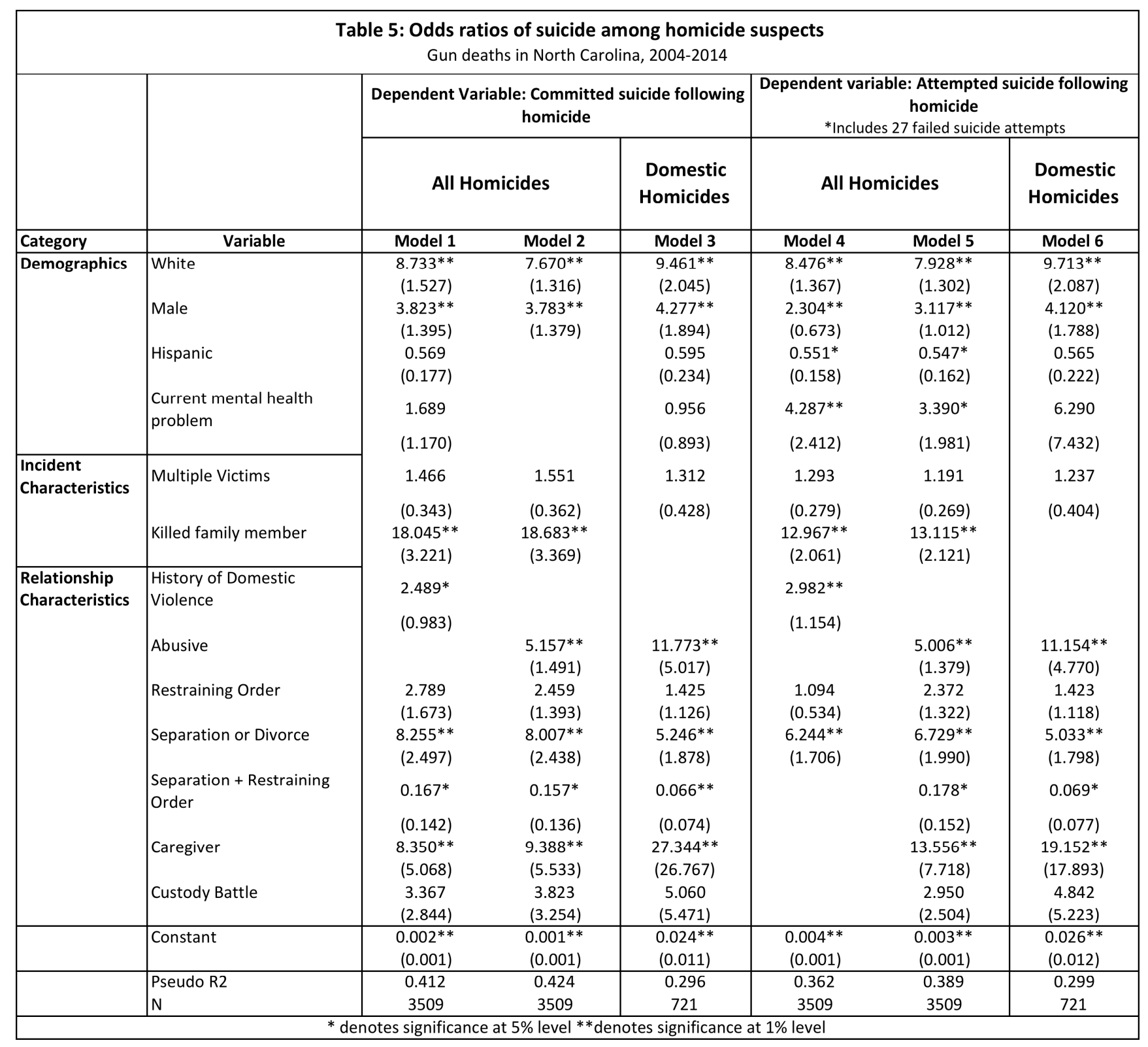

The odds of suicide following the homicide were 18 times greater if the perpetrator had killed a family member. If the killer was going through a separation or divorce, the odds of suicide were eight times higher following homicide. If the killer was the victim's caregiver, the odds of suicide following homicide were over nine times higher.

Neither a custody battle nor a restraining order had a significant effect on suicidal behavior among homicide perpetrators. The interaction of a restraining order and a separation was significant, and produces an odds ratio of 3.09 when multiplied by the odds estimates for the two variables.

When failed suicides are included in Model 5, mental illness becomes significantly predictive of suicidal behavior following homicide. Being Hispanic also becomes significant-Hispanic perpetrators had $45 \%$ lower odds of attempting suicide following homicide than non-Hispanic perpetrators.

Models 3 and 6 show odds ratios for suicide among homicide suspects in 721 domestic homicides. Within domestic homicides, a perpetrator with a history of being abusive was at over 11 times the odds of committing suicide following homicide. Caregivers had odds 27 times as high for a 
successful suicide attempt following homicide, and 19 times the odds of attempting suicide following homicide. However, while separation raised the odds of suicide following a domestic homicide by a factor of five, the odds that suicide followed homicide were halved if the victim had separated from the perpetrator and had a restraining order.

\section{Comparing Homicide-suicide perpetrators to other victims of firearm suicide}

Having established some key differences between solely homicidal individuals and homicidal-suicidal individuals, the analysis would not be complete without a comparison to solely suicidal individuals.

More than nine in ten solely suicidal individuals that committed suicide with a gun were white, and more than eight in ten were male. Of the homicidal-suicidal individuals, seven in ten were white, nearly three in ten were black, and nineteen in twenty were male. Proportionally fewer perpetrators of homicide-suicide were either over 65 or under 21 compared to other firearm suicides. Proportionally fewer firearm suicide victims were married or employed compared to perpetrators of homicide-suicide. Military members and divorced people were proportionally more frequent among firearm suicides than homicide-suicides (Figure 8).

Figure 8

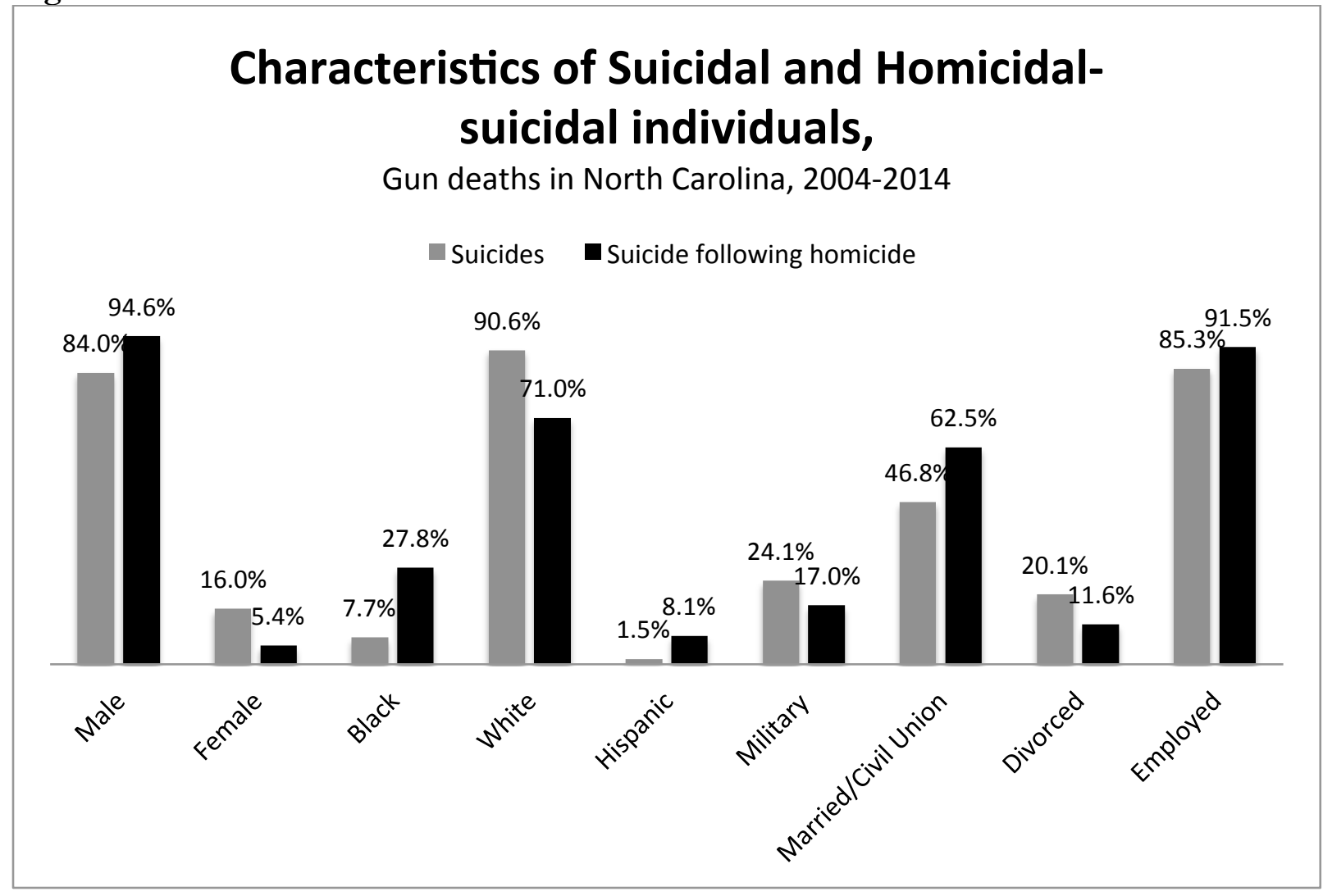

Compared to other suicidal individuals, homicidal-suicidal individuals were less likely to have any current or prior record of mental illness or mental health treatment (Figure 9). They were also less likely to have displayed any type of suicidal behavior compared to other suicidal individuals, including having left a note, expressed suicidal thoughts, made previous suicide attempts, or disclosed their suicidal intent in any way (Figure 10). 
Figure 9

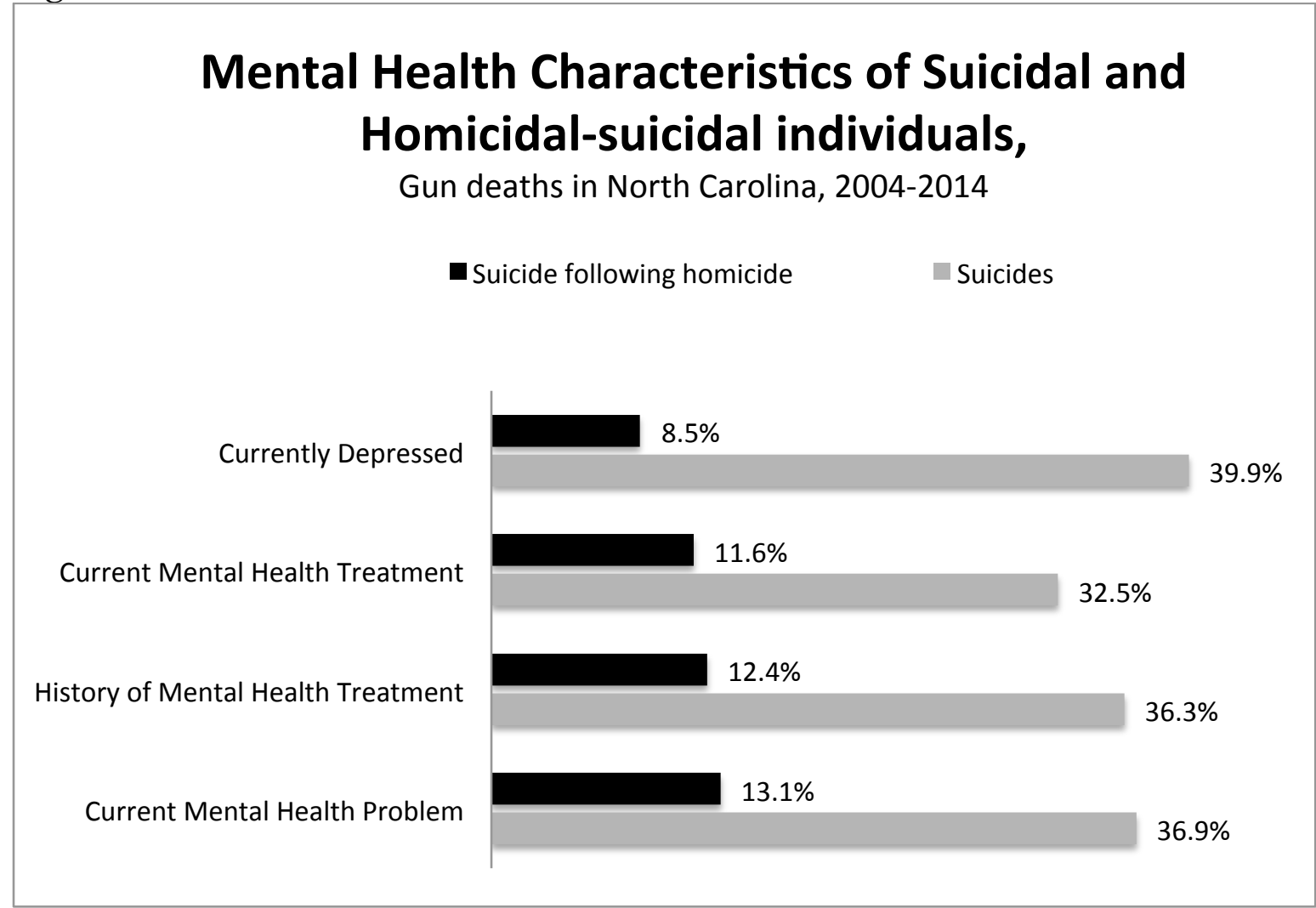

Figure 10

\section{Suicidal Behavior in Suicidal and Homicidal- suicidal individuals,} Gun deaths in North Carolina, 2004-2014

Suicide following homicide Suicides

Expressed sucidal thoughts

Left a suicide note

History of suicidal behavior

Disclosed suicidal intent
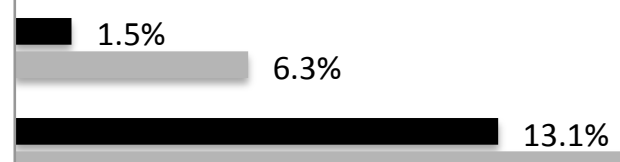

$9.0 \%$

$9.7 \%$

$24.1 \%$

Compared to other suicidal individuals, homicidal-suicidal individuals were more likely to have had a crisis in the two weeks preceding the incident or have a legal problem, but less likely to have a job problem, health problem, financial problem or have been using alcohol at the time of the incident (Figure 11). However, perpetrators of homicidal-suicide were proportionally far more likely to have an interpersonal problem, including a history of violence toward an intimate partner, a 
current problem with an intimate partner, a current family problem, or another relationship problem (Figure 12).

Figure 11

\section{Precipitating Circumstances in Suicides and Homicide-suicides}

Gun deaths in North Carolina, 2004-2014

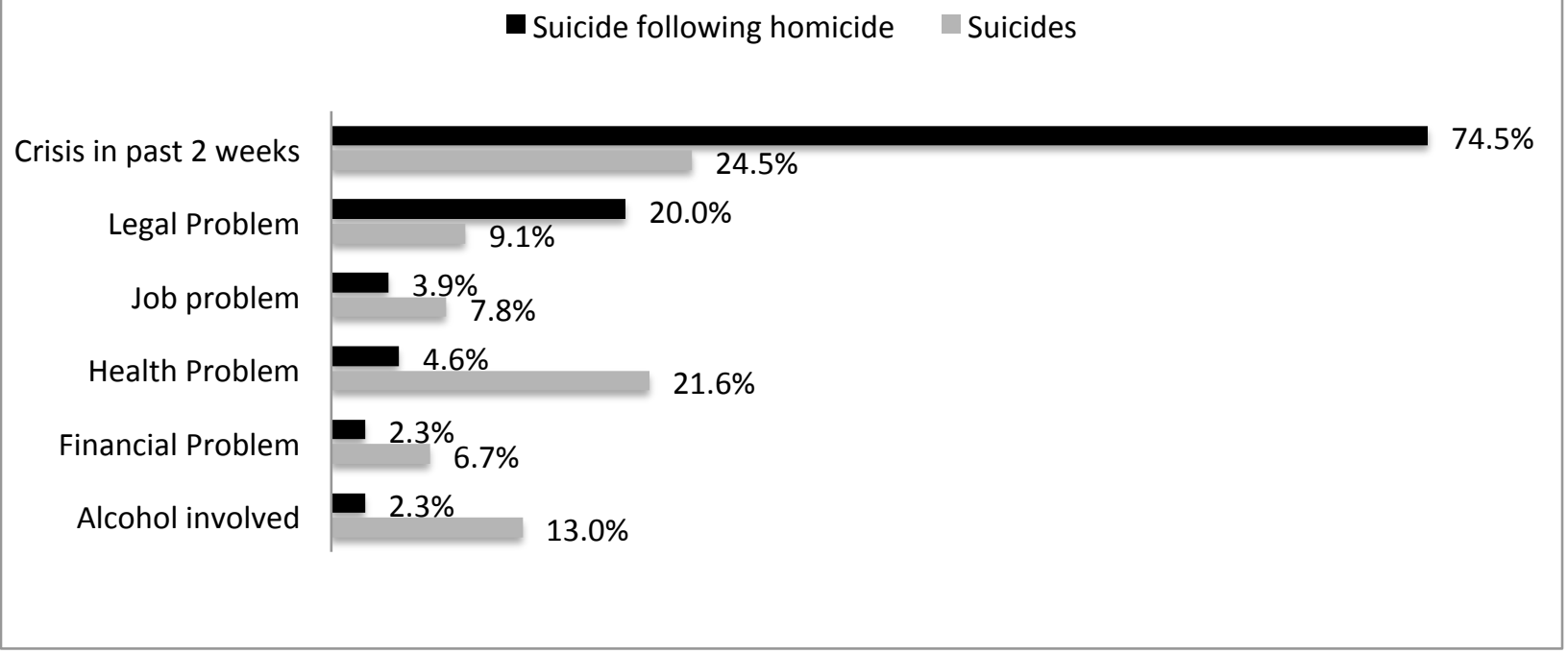

Figure 12

\section{Interpersonal Problems in Suicidal and Homicidal-suicidal individuals}

Gun deaths in North Carolina, 2004-2014

- Suicide following homicide Suicides

History of violence toward partner

$4.5 \%$

\section{$23.7 \%$}

$6.9 \%$

$2.4 \%$
Other relationship problem

Current problem with partner

Current family problem
$23.9 \%$

\section{$5.7 \%$}


Table 6 presents odds ratios of a suicidal person having committed homicide.

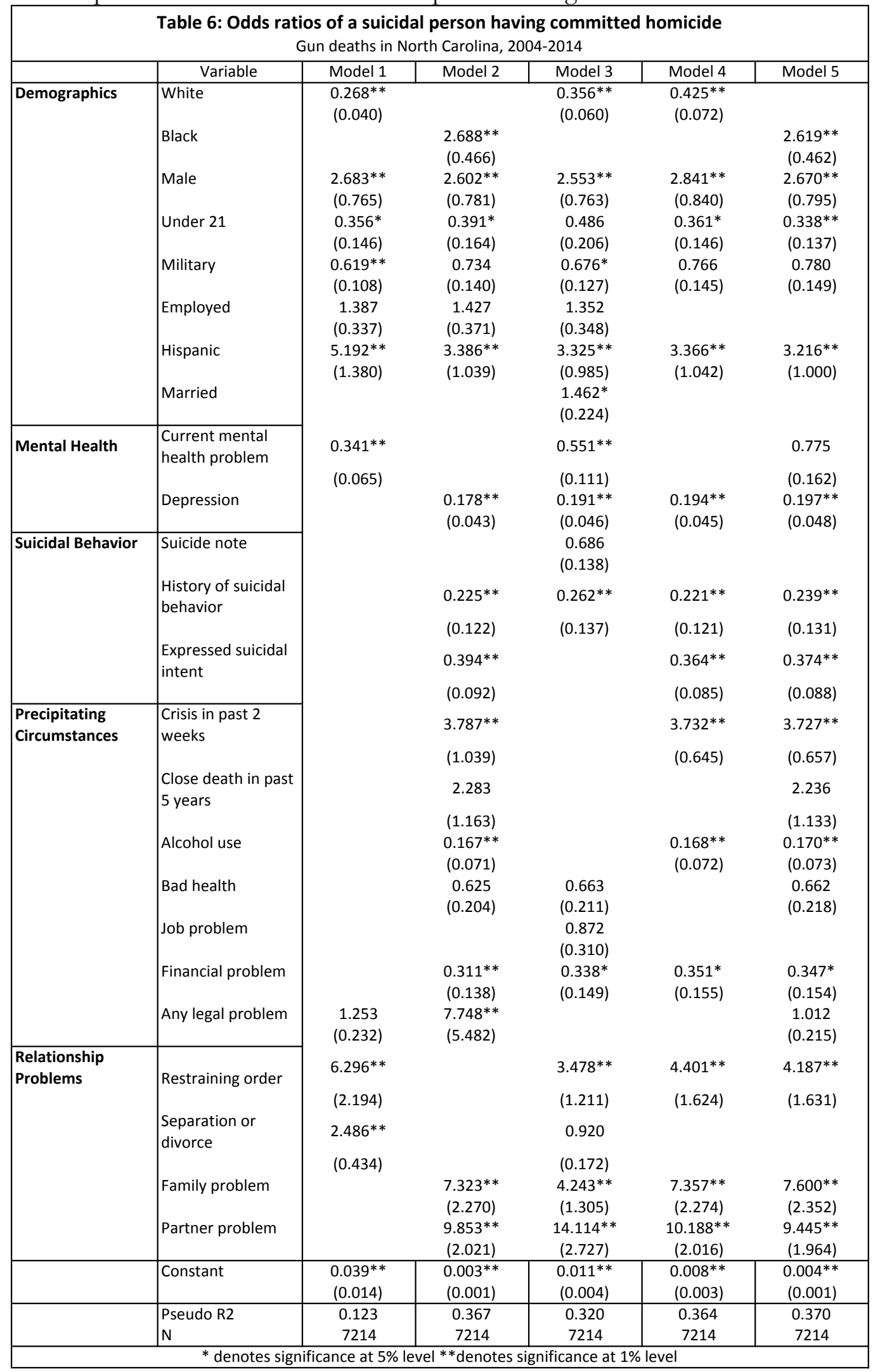


Model 5 shows that a suicidal person who is black has 2.6 times the odds of having committed homicide as well as suicide. Similarly, being Hispanic raises the odds of having committed homicide prior to suicide by over three times. Because firearm suicide is rare among minorities in North Carolina, and over $90 \%$ of firearm suicides during this time period were committed by whites, this finding makes sense. While men represented $85 \%$ of firearm suicides, they made up $95 \%$ of homicide-suicides. Suicidal males had 2.7 times the odds of suicidal females of having committed homicide. Suicidal individuals under the age of 21 had 66\% lower odds of being homicidal, compared to suicidal people over 21. The odds of homicide among suicidal people with a diagnosis of depression were $80 \%$ lower. A history of suicidal behavior, and the expression of suicidal intent both lowered the odds of homicide prior to suicide, by $77 \%$ and $63 \%$ respectively.

Suicidal people using alcohol at the time of death had $83 \%$ lower odds of having also been homicidal and suicidal people with financial problems had 65\% lower of having committed homicide.

A crisis in the two weeks prior to death raised the odds that homicide preceded suicide by 3.7. The presence of a restraining order at the time of death raised the odds of homicide within suicide by a factor of four. Having a partner problem, which includes a current separation or divorce, produced an odds ratio of a homicidal suicide by 9.5 times relative to suicide. Having a family problem raised the odds of homicide preceding suicide by 7.6 times.

\section{Conclusion}

The vast majority $(88 \%)$ of homicide-suicides targeted family members or current or former intimate partners. Approximately $12 \%$ of homicide-suicides targeted at least one person that was not an intimate partner or member of the perpetrator's family.

A large portion (42\%) of IPH cases ended in the perpetrator's suicide. Three quarters of homicidesuicides were IPH, and the majority of IPH cases that ended in the killer's suicide targeted a spouse $(58 \%)$. In fact, more spouses were killed in homicide-suicides than in simple homicides.

In 44 homicides, the perpetrator violated a restraining order. As a result, 55 people were murdered who should have been protected by a restraining order. Just over half of these victims (28) were killed in murder-suicides.

Homicide-suicide cases could be considered primarily suicides or primarily homicides. To consider these cases as a particular type of suicide, we would expect that suicidal killers have more in common with other suicidal individuals than with other homicidal individuals, particularly when considering suicidal behaviors and mental illness. To consider these cases primarily a type of homicide, we would expect that the suicide is incidental to the homicide, upon realization of consequences after the homicidal act. As indication that homicide-suicides are primarily homicidal, we might expect certain abusive patterns of behavior toward the victim to be an indication that murder was the primary intent.

The policy implications differ depending on whether homicide-suicides are primarily suicidal or primarily homicidal. If they are primarily suicidal, then the policy focus should be on treating mental illness effectively, and removing guns from depressed people and people with histories of suicidal behavior. If they are primarily homicidal, the policy focus should be on identifying abuse victims most at risk of homicide-suicide based on interactions with law enforcement, family court, and domestic violence shelters. Measures designed to prevent abusive individuals from possession or purchase of firearms would be especially helpful for the prevention of homicide-suicides if they are primarily homicidal.

The evidence here suggests that while homicide-suicides share elements with both homicide and suicide, they are distinct from either, but primarily motivated by homicidal intent. Perpetrators of homicide-suicide are less likely to have any history of mental illness or suicidal behavior than 
other suicidal individuals. If homicide-suicides were primarily suicidal, we would not expect to see such substantial differences along those lines. Homicidal-suicide perpetrators are less likely than other suicidal people to have financial problems, alcohol abuse or health problems. However, when comparing homicide-suicide perpetrators to both other homicide perpetrators and other suicidal individuals, homicidal-suicidal individuals are at far higher risk of having a serious interpersonal problem with the victim(s). These problems include separation or divorce, an abusive relationship, a restraining order, a custody battle, a caregiving relationship and a recent crisis.

Because the key predictors of homicide-suicide are characteristics of dysfunctional relationships between victim and perpetrator rather than characteristics that primarily reflect the perpetrator's personal problems, homicide-suicides can be understood as the culmination of toxic relationships. These crimes are largely determined by the intensity of the relationship between the victim and the killer.

The victim's identity in relationship to the killer plays an important role in homicide-suicide. Suicide is especially likely to follow the homicide of a spouse or child, suggesting that the killer is highly dependent on the victim and is unable to exist without them. This realization may prompt suicide in the aftermath of homicide. The pattern of escalating domestic violence that results in homicide-suicide indicates that homicide-suicides are primarily homicidal due to the intense fixation on the victim.

This analysis adds to evidence from several studies that suggest there are key points of intervention that could prevent domestic violence fatalities. Other studies have found that domestic violence incidents precede the majority of homicide-suicides and that many homicide-suicide victims seek aid from law enforcement in the year before their death. This analysis indicates that the presence of restraining orders in many cases demonstrates that many homicide-suicides are both predictable and preventable. The victims who sought legal recourse were sufficiently attuned to the pattern of escalating violence in their relationships to fear for their safety. Many sought restraining orders at the particularly dangerous moment of separation from their abuser. With better policies to screen for potentially fatal domestic violence scenarios, enforce restraining orders, and remove firearms from abusive individuals, these people might still be alive today.

The finding that restraining orders alone or combined with separation between victim and killer increase the odds of homicide-suicide relative to both homicide and suicide bears further investigation. This may indicate that victims are better at discerning the type of violence that might lead to a homicide-suicide and acting on that knowledge, or it may indicate that the victims of homicide-suicides, most of whom are white females, feel more empowered to avail themselves of legal resources. Conversely, it may indicate that a restraining order has a particular effect on the perpetrator, making them more likely to commit suicide following homicide. It is important to emphasize that nothing in this analysis indicates that a restraining order puts a victim in more danger than they would otherwise be in. However, the fact that over ten years, 55 North Carolinians who were under the protection of a restraining order lost their lives in a homicide is of great concern and suggests that more action could be taken to better enforce protective orders.

Future research should investigate how law enforcement agencies enforce restraining orders, how effectively they manage to separate abusers from guns, and whether ex parte restraining orders reduce homicides and homicide-suicides when considered separately from permanent restraining orders.

This project initially sought to examine homicide-suicides on the basis that the study of mass shootings may benefit from insights gleaned from homicide-suicides, since many mass shootings include domestic violence and culminate in the suicide or death of the shooter. While there is scant evidence on mass shootings in general, and only five incidents that meet the FBI definition of a mass shooting in this data set, one in six murder-suicides in North Carolina between 2004-2014 targeted at least one victim outside of the killer's family. Future research could use NVDRS data 
from multiple states to investigate these extra-familial cases to establish risk factors for nondomestic homicide-suicides. These cases may provide more applicable links to mass shootings than studies of homicide-suicide overall, which are largely contained to families.

This analysis adds to the pantheon of evidence that domestic violence and abuse are important risk factors for gun violence, especially for women. Orders of protection ought to be taken seriously and enforced rigorously. Between 2004 and 2014, North Carolina lost over 700 citizens to domestic gun violence, and 500 to intimate partner homicide. Many of these victims had contact with law enforcement before their deaths, and many more had friends or relatives with knowledge of the abuse they suffered. Some cases of fatal gun violence are preventable through strengthening policies that aid victims of domestic violence. North Carolina should look to the examples of states like California that have pioneered strict gun laws to protect victims of domestic violence.

Reexamining the Summers case from a policy standpoint yields several points that may improve state policies to prevent homicide-suicides. At the point that Michael Summers shot his wife, Jennifer, before killing himself, there had been multiple points of contact with the legal system. Jennifer had secured a restraining order against Michael, and had subsequently dropped it following Michael's custody suit. As we know from the literature, abusers use custody disputes to pressure their victims to drop restraining orders and force contact. This is a pattern that ought to raise a particular red flag to law enforcement as being an indication of an abusive relationship that should be monitored. Cases that follow this pattern should receive particular screening, follow-up from law enforcement, or case management. Custody court should not require both parties to be present if one has a restraining order against the other. In cases where one parent is under a restraining order protecting the other, child custody should be assigned to the parent under the protective order.

Jennifer's restraining order petition also noted the presence of guns in the home. Certain states require law enforcement to confiscate the firearms of people barred from purchase or possession due to a restraining order. If North Carolina had a similar law in place, Michael might have been separated from his guns. With a law that did not require Jennifer's presence in custody court, perhaps she would not have dropped the restraining order and Michael would not have regained access to his guns. While these hypothetical scenarios cannot help the Summers', it is not difficult to imagine that such laws could prevent other violent deaths. The Summers case provides a good illustration of several key patterns of violence that are typical of homicide-suicides, some of which are amenable to policy action.

Based on the findings of this analysis and others, North Carolina could consider passing legislation to: protect dating partners and family members under permanent and ex parte domestic violence restraining orders, prohibit convicted stalkers and abusers from possession and purchase of firearms, require the confiscation of guns present at the scene of domestic violence calls, enable law enforcement to confiscate guns from those prohibited from having them, and develop a method to screen for and monitor domestic violence cases that have a high risk of fatal escalation. 


\section{Appendix 1: Descriptive Tables}

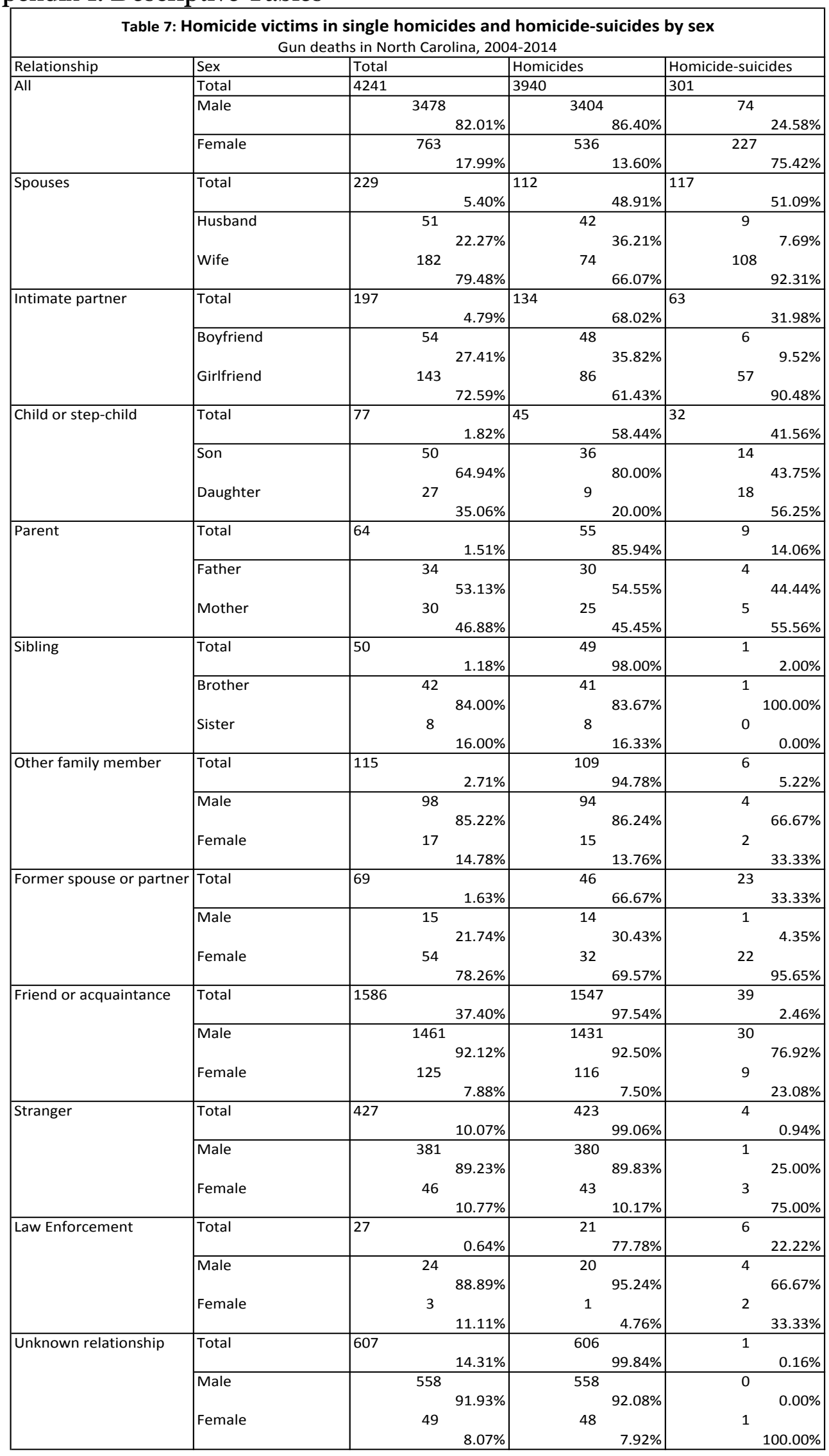




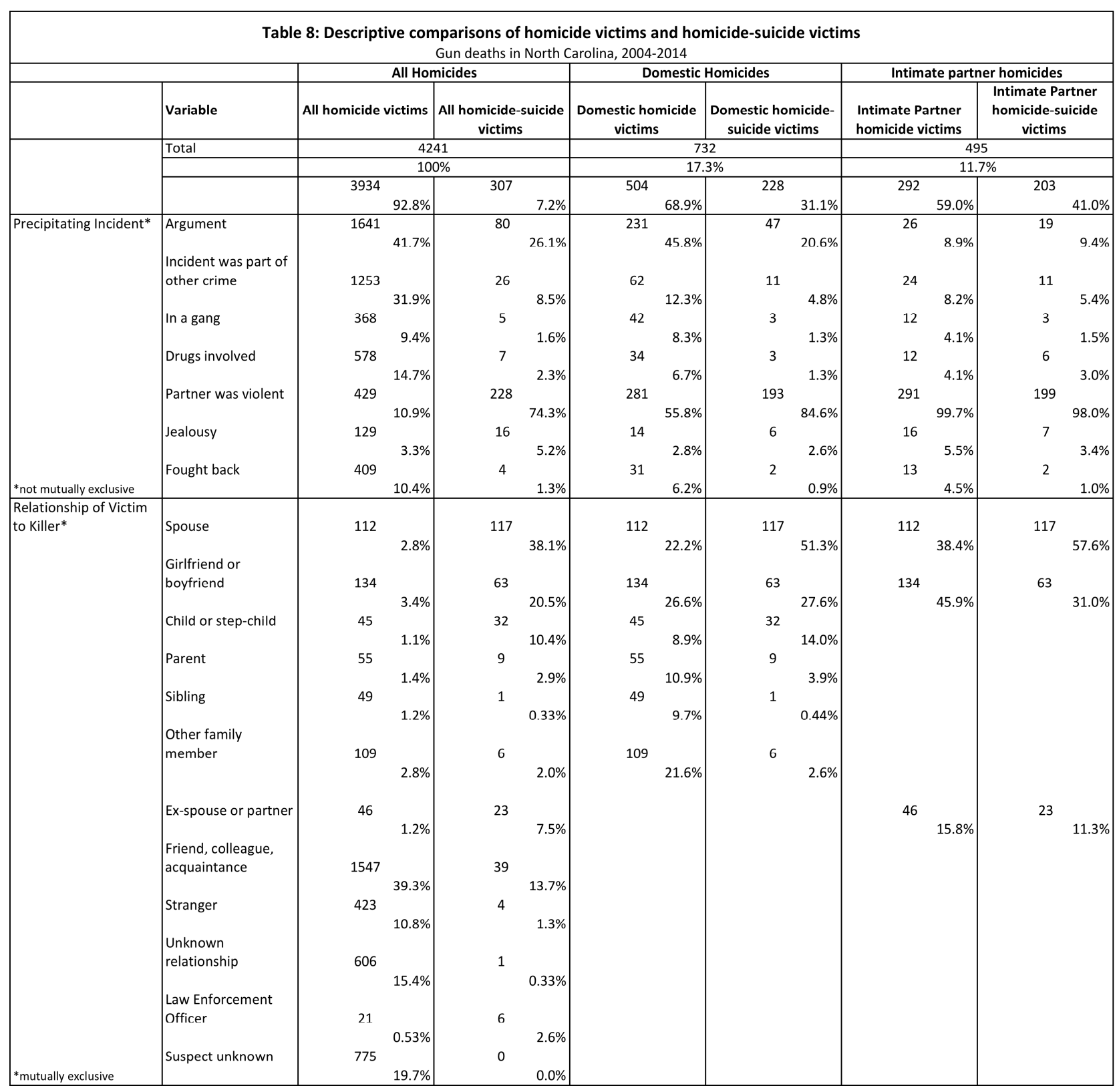




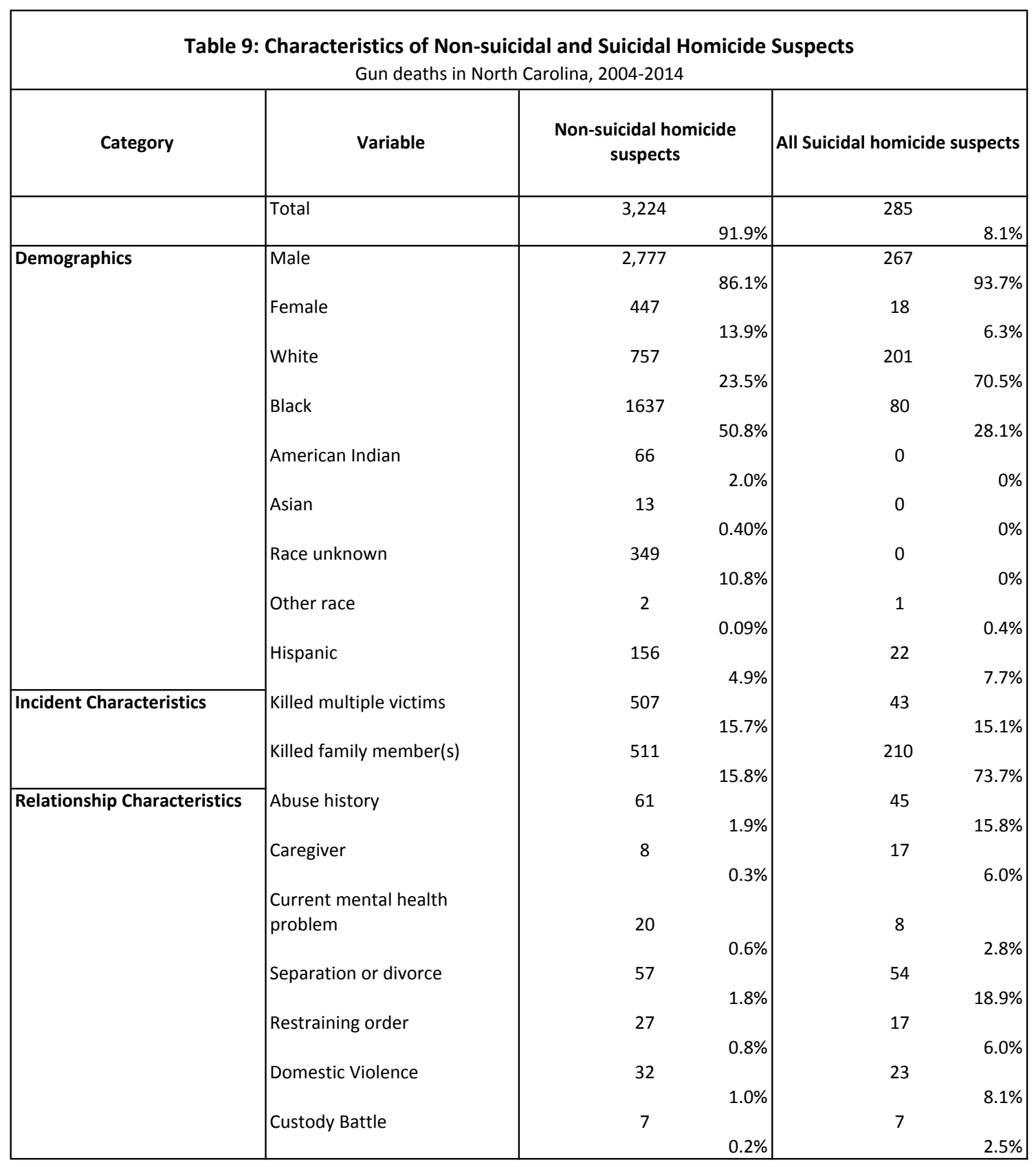




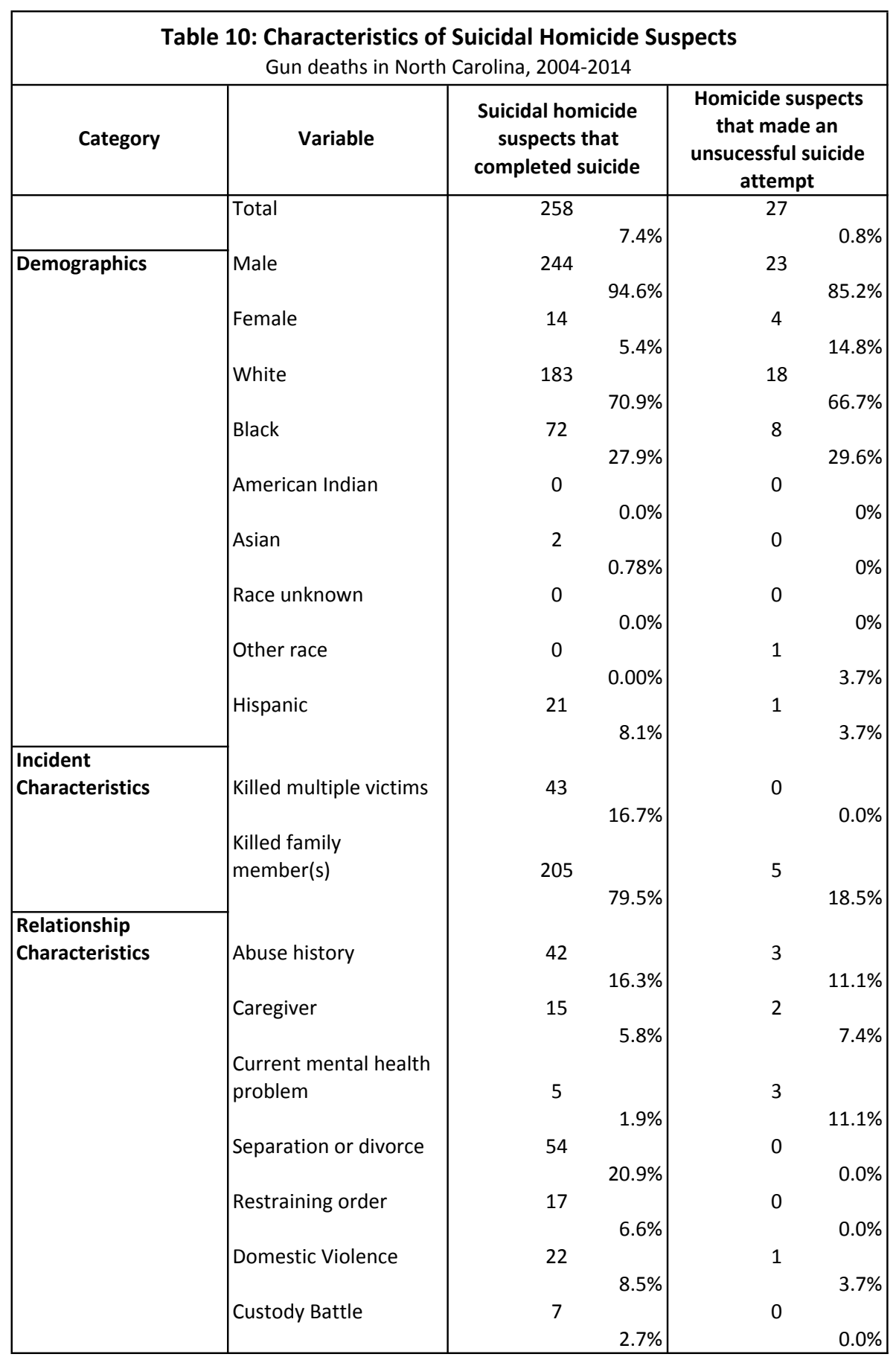




\begin{tabular}{|c|c|c|c|c|c|c|c|}
\hline Category & Variable & Suicides only & $\begin{array}{c}\text { Suicide } \\
\text { Following } \\
\text { Murder }\end{array}$ & Murders only & $\begin{array}{c}\text { Murder } \\
\text { Followed by } \\
\text { Suicide }\end{array}$ & $\begin{array}{c}\text { Domestic } \\
\text { Murder }\end{array}$ & $\begin{array}{c}\text { Domestic } \\
\text { Murder } \\
\text { Followed by } \\
\text { Suicide }\end{array}$ \\
\hline & \begin{tabular}{|l|} 
Total \\
Of total cases
\end{tabular} & $\begin{array}{r}6955 \\
60.7 \% \\
\end{array}$ & 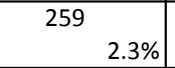 & $\begin{array}{r}3934 \\
34.3 \%\end{array}$ & 307 & $\begin{aligned} & 552 \\
& 14.0 \% \\
&\end{aligned}$ & $\begin{array}{r}228 \\
\quad 74.3 \%\end{array}$ \\
\hline Sex & $\begin{array}{l}\text { Male } \\
\text { Female }\end{array}$ & \begin{tabular}{|c|}
5842 \\
$84.0 \%$ \\
1113 \\
$16.0 \%$ \\
\end{tabular} & $\begin{array}{|lr|}245 & \\
& 94.6 \% \\
14 & \\
& 5.4 \% \\
\end{array}$ & \begin{tabular}{|c|}
3398 \\
\multicolumn{2}{|c|}{$86.4 \%$} \\
536 \\
\\
$13.6 \%$ \\
\end{tabular} & 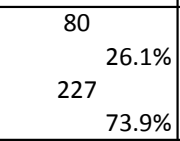 & $\begin{array}{|rr|}287 & \\
217 & \\
217.0 \% \\
& 39.3 \% \\
\end{array}$ & $\begin{array}{lr}38 & \\
190.7 \% \\
83.3 \%\end{array}$ \\
\hline Ethnicity & Hispanic & 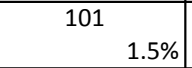 & $\begin{array}{|ll|}21 & \\
& 8.1 \% \\
\end{array}$ & \begin{tabular}{|r|r|}
387 & \\
& $9.8 \%$ \\
\end{tabular} & 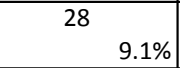 & 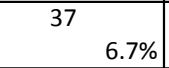 & $\begin{array}{ll}19 & \\
& 8.3 \% \\
\end{array}$ \\
\hline Race & $\begin{array}{l}\text { Black } \\
\text { White } \\
\text { American Indian } \\
\text { Asian } \\
\text { Other race }\end{array}$ & $\begin{array}{cc}539 & \\
& 7.7 \% \\
6300 & \\
& 90.6 \% \\
62 & \\
& 0.9 \% \\
33 & \\
& 0.5 \% \\
21 & \\
& 0.30 \% \\
\end{array}$ & \begin{tabular}{cr|}
72 & \\
& $27.8 \%$ \\
184 & \\
& $71.0 \%$ \\
0 & \\
& $0.0 \%$ \\
2 & \\
& $0.8 \%$ \\
1 & \\
& $0.39 \%$ \\
\end{tabular} & 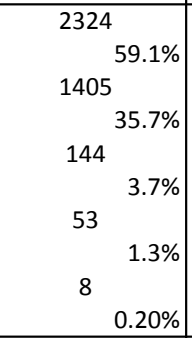 & $\begin{array}{|cc|}78 & \\
& 25.4 \% \\
224 & \\
& 73.0 \% \\
3 & \\
& 1.0 \% \\
2 & \\
& 0.7 \% \\
0 & \\
& 0.00 \% \\
\end{array}$ & $\begin{array}{|rr|}181 & \\
& 32.8 \% \\
341 & \\
& 61.8 \% \\
23 & \\
& 4.2 \% \\
7 & \\
& 1.3 \% \\
0 & \\
& 0 \% \\
\end{array}$ & $\begin{array}{cr}52 & \\
& 22.8 \% \\
172 & \\
& 75.4 \% \\
2 & \\
& 0.9 \% \\
2 & \\
& 0.9 \% \\
0 & \\
& 0 \%\end{array}$ \\
\hline Age & $\begin{array}{l}\text { Under } 21 \\
\text { Over } 65\end{array}$ & $\begin{array}{|rr|}378 & \\
& 5.4 \% \\
1491 & \\
& 21.4 \% \\
\end{array}$ & $\begin{array}{|cc|}7 & \\
& 2.7 \% \\
25 & \\
& 9.7 \% \\
\end{array}$ & 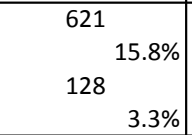 & $\begin{array}{|cc|}50 & \\
& 16.3 \% \\
27 & \\
& 8.8 \% \\
\end{array}$ & $\begin{array}{|cc|}75 & \\
& 13.6 \% \\
48 & \\
& 8.7 \% \\
\end{array}$ & $\begin{array}{lr}34 & \\
& 14.9 \% \\
24 & \\
& 10.5 \%\end{array}$ \\
\hline Background & 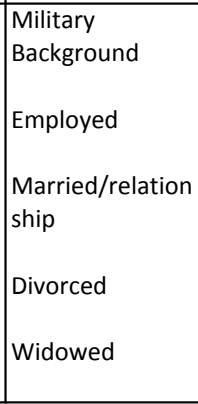 & 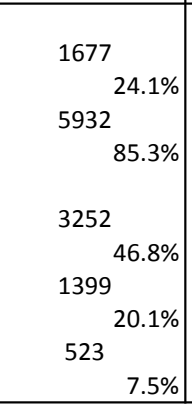 & $\begin{array}{cc}44 & \\
& 17.0 \% \\
237 & \\
& 91.5 \% \\
& \\
162 & \\
& 62.5 \% \\
30 & \\
& 11.6 \% \\
2 & \\
& 0.8 \%\end{array}$ & \begin{tabular}{cc}
271 & \\
& $6.9 \%$ \\
2959 & \\
& $75.2 \%$ \\
& \\
941 & \\
\multicolumn{2}{|c}{$23.9 \%$} \\
388 & \\
& $9.9 \%$ \\
29 & \\
& $9.9 \%$
\end{tabular} & $\begin{array}{cc}167 & \\
& 54.4 \% \\
30 & \\
& 9.8 \% \\
1 & \\
& 0.3 \% \\
\end{array}$ & $\begin{array}{cc}241 & \\
& 43.7 \% \\
82 & \\
& 14.9 \% \\
9 & \\
& 1.6 \%\end{array}$ & $\begin{array}{cc}141 & \\
& 61.8 \% \\
21 & \\
& 9.2 \% \\
1 & \\
& 0.4 \% \\
\end{array}$ \\
\hline
\end{tabular}


Table 12: Personal characteristics and precipitating incidents in suicide and homicide-suicide Gun deaths in North Carolina, 2004-2014

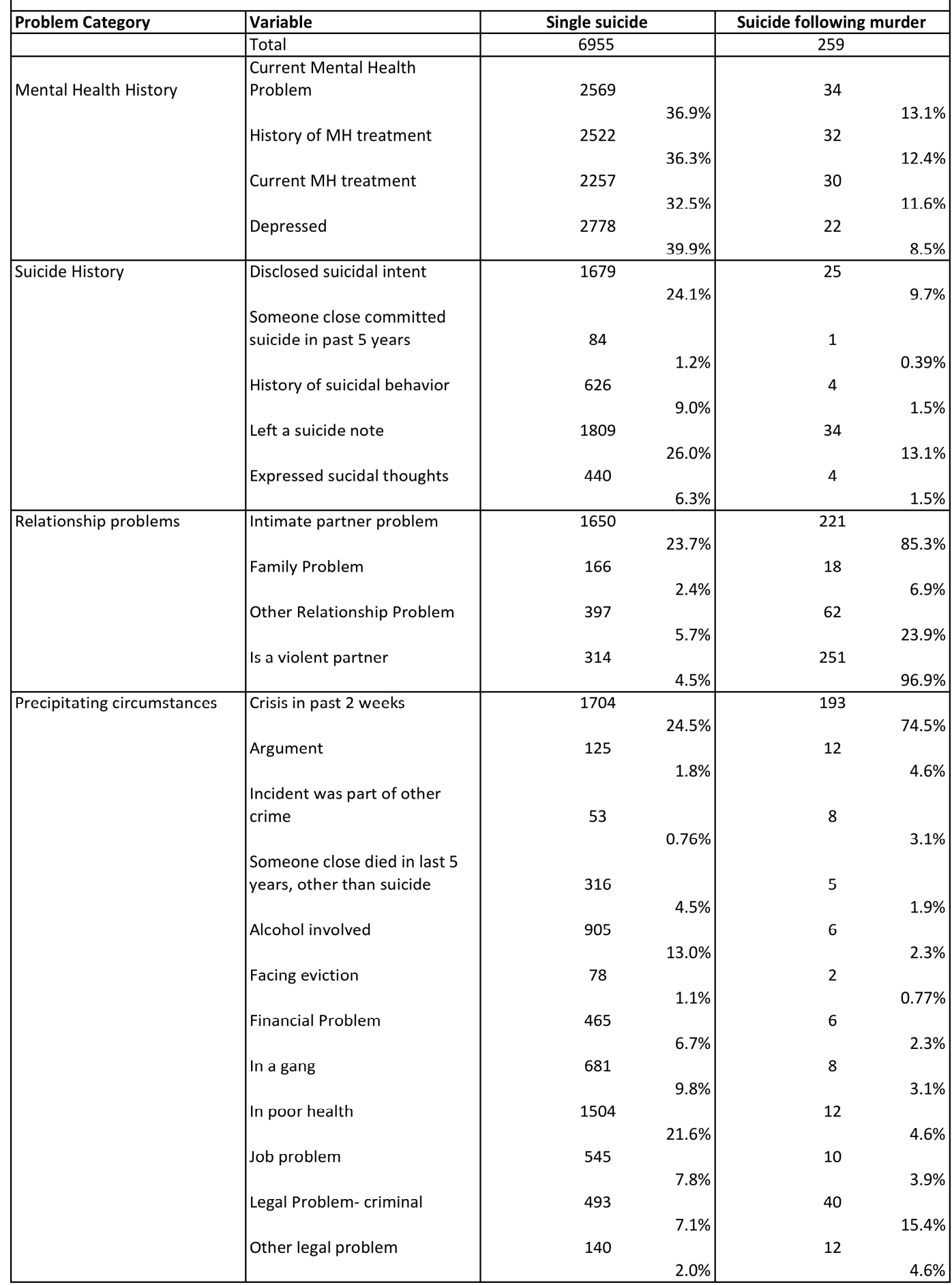




\section{Bibliography}

“Analysis of Mass Shootings.” EverytownResearch.org. Accessed November 20, 2015. http:/ / everytownresearch.org/reports/mass-shootings-analysis/.

Anderson, M., J. Kaufman, T. R. Simon, L. Barrios, L. Paulozzi, G. Ryan, R. Hammond, et al. "SchoolAssociated Violent Deaths in the United States, 1994-1999." JAMA 286, no. 21 (December 5, 2001): 2695-2702.

"A Study of Active Shooter Incidents in the United States Between 2000 and 2013," U.S. Department of Justice, Federal Bureau of Investigation, 2014, https://www.fbi.gov/news/stories/2014/september/fbireleases-study-on-active-shooter-incidents/pdfs/a-study-of-active-shooter-incidents-in-the-u.s.between-2000-and-2013

Appelbaum, Paul S., and Jeffrey W. Swanson. "Law \& Psychiatry: Gun Laws and Mental Illness: How Sensible Are the Current Restrictions?” Psychiatric Services 61, no. 7 (July 1, 2010): 652-54. doi:10.1176/ps.2010.61.7.652.

Azrael, Deborah, Catherine Barber, and James Mercy. "Linking data to save lives: recent progress in establishing a National Violent Death Reporting System." Harvard Health Policy Review 2, no. 2 (2001): 38-42.

Barber, Catherine W., Deborah Azrael, David Hemenway, Lenora M. Olson, Carrie Nie, Judy Schaechter, and Sabrina Walsh. "Suicides and Suicide Attempts Following Homicide Victim-Suspect Relationship, Weapon Type, and Presence of Antidepressants." Homicide Studies 12, no. 3 (August 1, 2008): 285-97. doi:10.1177/1088767908319597.

Berk, Richard A., Alec Campbell, Ruth Klap, and Bruce Western. "The Deterrent Effect of Arrest in Incidents of Domestic Violence: A Bayesian Analysis of Four Field Experiments." American Sociological Review 57, no. 5 (1992): 698-708. doi:10.2307/2095923.

Bossarte, R. M., T. R. Simon, and L. Barker. "Characteristics of Homicide Followed by Suicide Incidents in Multiple States, 2003-04.” Injury Prevention 12, no. suppl 2 (December 1, 2006): ii33-38. doi:10.1136/ip.2006.012807.

Brent, David A. "Firearms and Suicide." Annals of the New York Academy of Sciences 932, no. 1 (April 1, 2001): 225-40. doi:10.1111/j.1749-6632.2001.tb05808.x.

Buchanan, Larry, Keller, Josh, Oppel Jr., Richard A., and Victor, Daniel. "How They Got Their Guns," The New York Times, October 3, 2015, http://www.nytimes.com/interactive/2015/10/03/us/howmass-shooters-got-their-guns.html

Buteau, Jacques, Alain D. Lesage, and Margaret C. Kiely. "Homicide Followed by Suicide: A Quebec Case Series, 1988-1990." The Canadian Journal of Psychiatry / La Revue Canadienne de Psychiatrie 38, no. 8 (1993): 552-56.

“California Wait Period Doesn't Apply to Gun Owners.” KCRA. Accessed December 11, 2015. http://www.kcra.com/politics/california-wait-period-doesnt-apply-to-gun-owners/27726554.

"California State Law Summary." Law Center to Prevent Gun Violence. October 29, 2015. Accessed December 10, 2015. http://smartgunlaws.org/california-state-law-summary/

Campbell, Jacquelyn C., Nancy Glass, Phyllis W. Sharps, Kathryn Laughon, and Tina Bloom. "Intimate Partner Homicide Review and Implications of Research and Policy." Trauma, Violence, \& Abuse 8, no. 3 (July 1, 2007): 246-69. doi:10.1177/1524838007303505.

Campbell, Jacquelyn C., Daniel Webster, Jane Koziol-McLain, Carolyn Block, Doris Campbell, Mary Ann Curry, Faye Gary, et al. "Risk Factors for Femicide in Abusive Relationships: Results From a Multisite Case Control Study." American Journal of Public Health 93, no. 7 (July 2003): 1089-97.

Cook, Philip J., and Kristin A. Goss. The Gun Debate: What Everyone Needs to Know. Oxford University Press, 2014. 
Cook, Philip J., and Jens Ludwig. Guns in America: results of a comprehensive national survey on firearms ownership and use. Washington, DC: Police Foundation, 1996.

Cook, Philip J., and Jens Ludwig. "The Social Costs of Gun Ownership." Journal of Public Economics 90, no. 1-2 (January 2006): 379-91. doi:10.1016/j.jpubeco.2005.02.003.

"Couple Found Dead in Johnston County Shooting." ABC11 Raleigh-Durham. November 24, 2015. Accessed April 14, 2016. http:/ /abc11.com/1096956/.

Dahlberg, Linda L., Robin M. Ikeda, and Marcie-jo Kresnow. "Guns in the Home and Risk of a Violent Death in the Home: Findings from a National Study." American Journal of Epidemiology 160, no. 10 (November 15, 2004): 929-36. doi:10.1093/aje/kwh309.

“Domestic Violence and Firearms Policy Summary." Law Center to Prevent Gun Violence. May 11, 2014. Accessed April 15, 2016. http://smartgunlaws.org/domestic-violence-firearms-policy-summary/

Duwe, Grant. "The Patterns and Prevalence of Mass Murder in Twentieth-Century America." Justice Quarterly: JQ 21, no. 4 (December 2004): 729-61.

Eliason, Scott. "Murder-Suicide: A Review of the Recent Literature." Journal of the American Academy of Psychiatry and the Law Online 37, no. 3 (September 1, 2009): 371-76.

Faria, Miguel. "Shooting Rampages, Mental Health, and the Sensationalization of Violence." Surgical Neurology International 4 (2013): 16-16. doi:http:/ / dx.doi.org.proxy.lib.duke.edu/10.4103/21527806.106578.

Fox, James Alan, and Monica J. DeLateur. "Mass Shootings in America Moving Beyond Newtown." Homicide Studies 18, no. 1 (February 1, 2014): 125-45. doi:10.1177/1088767913510297.

Frattaroli, Shannon, Emma E. McGinty, Amy Barnhorst, and Sheldon Greenberg. "Gun Violence Restraining Orders: Alternative or Adjunct to Mental Health-Based Restrictions on Firearms?" Behavioral Sciences \& the Law 33, no. 2-3 (June 1, 2015): 290-307. doi:10.1002/bsl.2173.

Gold, Sharon L. "Why Are Victims of Domestic Violence Still Dying at the Hands of Their Abusers Filling the Gap in State Domestic Violence Gun Laws.” Kentucky Law Journal 91 (2003 2002): 935.

"Gun Violence by the Numbers." EverytownResearch.org. Accessed December 11, 2015. http:/ / everytownresearch.org/gun-violence-by-the-numbers/.

Horwitz, Joshua, Anna Grilley, and Orla Kennedy. "Beyond the Academic Journal: Unfreezing Misconceptions About Mental Illness and Gun Violence Through Knowledge Translation to Decision-Makers." Behavioral Sciences \& the Law 33, no. 2-3 (June 1, 2015): 356-65. doi:10.1002/bsl.2176.

Jackson, Drew. "Restraining Order Preceded Summers Murder-Suicide." News Observer. Accessed April 14, 2016. http://www.newsobserver.com/news/local/counties/johnstoncounty/article46708775.html.

Jaffe, Peter G., Janet R. Johnston, Claire V. Crooks, and Nicholas Bala. “Custody Disputes Involving Allegations of Domestic Violence: Toward a Differentiated Approach to Parenting Plans.” Family Court Review 46, no. 3 (July 1, 2008): 500-522. doi:10.1111/j.1744-1617.2008.00216.x.

"Johnston County Couple Killed in Murder-Suicide : WRAL.com." November 25, 2015. Accessed April 14, 2016. http://www.wral.com/couple-killed-in-clayton-murder-suicide/15132568/.

Kalish, Rachel, and Michael Kimmel. "Suicide by Mass Murder: Masculinity, Aggrieved Entitlement, and Rampage School Shootings.” Health Sociology Review 19, no. 4 (December 2010): 451+.

Kaplan, M. S., B. H. McFarland, and N. Huguet. "Characteristics of Adult Male and Female Firearm Suicide Decedents: Findings from the National Violent Death Reporting System.” Injury Prevention 15, no. 5 (October 1, 2009): 322-27. doi:10.1136/ip.2008.021162.

Kellermann, Arthur L., Frederick P. Rivara, Norman B. Rushforth, Joyce G. Banton, Donald T. Reay, Jerry T. Francisco, Ana B. Locci, Janice Prodzinski, Bela B. Hackman, and Grant Somes. "Gun ownership as a risk factor for homicide in the home." New England Journal of Medicine 329, no. 15 (1993): 1084-1091. 
Knoll, James L. “The 'Pseudocommando' Mass Murderer: Part II, The Language of Revenge.” Journal of the American Academy of Psychiatry and the Law Online 38, no. 2 (June 1, 2010): 263-72.

Koziol-McLain, Jane, Daniel Webster, Judith McFarlane, Carolyn Rebecca Block, and et al. "Risk Factors for Femicide-Suicide in Abusive Relationships: Results From a Multisite Case Control Study." Violence and Victims 21, no. 1 (February 2006): 3-21.

Lang, Matthew. "Firearm Background Checks and Suicide." The Economic Journal 123, no. 573 (December 1, 2013): 1085-99. doi:10.1111/ecoj.12007.

Lankford, Adam. "A Comparative Analysis of Suicide Terrorists and Rampage, Workplace, and School Shooters in the United States From 1990 to 2010.” Homicide Studies 17, no. 3 (August 1, 2013): 25574. doi:10.1177/1088767912462033.

LeFevre-Sillito, Carrie, and Sonia Salari. "Child outcomes and risk factors in US homicide-suicide cases 1999-2004." Journal of Family Violence 26, no. 4 (2011): 285-297.

Lemieux, Frederic. "Effect of Gun Culture and Firearm Laws on Gun Violence and Mass Shootings in the United States: A Multi-Level Quantitative Analysis." International Journal of Criminal Justice Sciences 9, no. 1 (June 2014): 74-93.

Liem, Marieke, Michiel Hengeveld, and Frans Koenraadt. "Domestic Homicide Followed by Parasuicide: A Comparison With Homicide and Parasuicide.” International Journal of Offender Therapy and Comparative Criminology, April 20, 2009. doi:10.1177/0306624X09334646.

Liem, Marieke, and Darryl W. Roberts. "Intimate Partner Homicide by Presence or Absence of a SelfDestructive Act.” Homicide Studies 13, no. 4 (November 1, 2009): 339-54. doi:10.1177/1088767909347988.

Logan, J., Holly A. Hill, Michele Lynberg Black, Alex E. Crosby, Debra L. Karch, Jamar D. Barnes, and Keri M. Lubell. "Characteristics of Perpetrators in Homicide-Followed-by-Suicide Incidents: National Violent Death Reporting System-17 US States, 2003-2005.” American Journal of Epidemiology 168, no. 9 (November 1, 2008): 1056-64. doi:10.1093/aje/kwn213.

Lund, Laura E., and Svetlana Smorodinsky. "Violent Death Among Intimate Partners: A Comparison of Homicide and Homicide Followed by Suicide in California." Suicide and Life-Threatening Behavior 31, no. 4 (December 1, 2001): 451-59. doi:10.1521/suli.31.4.451.22046.

Malphurs, Julie E., and Donna Cohen. "A newspaper surveillance study of homicide-suicide in the United States." The American Journal of Forensic Medicine and Pathology 23.2 (2002): 142-148.

Malphurs, Julie E., Carl Eisdorfer, and Donna Cohen. "A Comparison of Antecedents of HomicideSuicide and Suicide in Older Married Men." The American Journal of Geriatric Psychiatry 9, no. 1 (2001): 49-57. doi:10.1097/00019442-200102000-00008.

Marzuk PM, Tardiff K, and Hirsch CS. "The Epidemiology of Murder-Suicide." JAMA 267, no. 23 (June 17, 1992): 3179-83. doi:10.1001/jama.1992.03480230071031.

Maxson, Cheryl L., Margaret A. Gordon, and Malcolm W. Klein. "Differences between Gang an Nongang Homicides." Criminology 23 (1985): 209.

"Mental Health Reporting Policy Summary", Law Center to Prevent Gun Violence, September 16, 2013, http:/ / smartgunlaws.org/mental-health-reporting-policy-summary/

"Mental Illnesses”, National Alliance of Mental Illness, 2015. http://www2.nami.org/Content/NavigationMenu/Inform_Yourself/About_Mental_Illness/By_Ill ness/Suicide.htm.

Metzl, Jonathan M., and Kenneth T. MacLeish. "Mental Illness, Mass Shootings, and the Politics of American Firearms." American Journal of Public Health 105, no. 2 (February 2015): 240-49.

Miller, Matthew, Deborah Azrael, and David Hemenway. "Household Firearm Ownership and Suicide Rates in the United States.” Epidemiology 13, no. 5 (September 1, 2002): 517-24.

Miller, Matthew, Deborah Azrael, and David Hemenway. "Rates of household firearm ownership and homicide across US regions and states, 1988-1997." American journal of public health 92, no. 12 (2002): 1988-1993. 
Miller, Matthew, and David Hemenway. "Guns and Suicide in the United States." New England Journal of Medicine 359, no. 10 (September 4, 2008): 989-91. doi:10.1056/NEJMp0805923.

Milroy, C. M. "Homicide Followed by Suicide: Remorse or Revenge?" Journal of Clinical Forensic Medicine 5, no. 2 (June 1998): 61-64. doi:10.1016/S1353-1131(98)90054-2.

Milroy, C. M. “The Epidemiology of Homicide-Suicide (dyadic Death).” Forensic Science International 71, no. 2 (January 30, 1995): 117-22. doi:10.1016/0379-0738(94)01648-O.

Moracco, Kathryn E., Carol W. Runyan, and John D. Butts. "Femicide in North Carolina, 1991-1993 A Statewide Study of Patterns and Precursors.” Homicide Studies 2, no. 4 (November 1, 1998): 422-46. doi:10.1177/1088767998002004005.

Morton, Emma, Carol W. Runyan, Kathryn E. Moracco, and John Butts. "Partner Homicide-Suicide Involving Female Homicide Victims: A Population- Based Study in North Carolina, 1988-1992." Violence and Victims 13, no. 2 (January 1, 1998): 91-106.

"National Violent Death Reporting System." Centers for Disease Control and Prevention. June 18, 2015. Accessed April 7, 2016. http://www.cdc.gov/violenceprevention/nvdrs/

“The NICS Improvement Amendments Act of 2007."Bureau of Justice Statistics, October 4, 2015, http:/ / www.bjs.gov/index.cfm?ty=tp\&tid $=49$

Orri, Massimiliano, Matteo Paduanello, Jonathan Lachal, Bruno Falissard, Jordan Sibeoni, and Anne Revah-Levy. "Qualitative Approach to Attempted Suicide by Adolescents and Young Adults: The (Neglected) Role of Revenge: e96716.” PLoS One 9, no. 5 (May 2014). doi:http://dx.doi.org.proxy.lib.duke.edu/10.1371/journal.pone.0096716.

Palmer, Stuart, and John A. Humphrey. "Offender-Victim Relationships in Criminal Homicide Followed by Offender's Suicide, North Carolina, 1972-1977." Suicide and Life-Threatening Behavior 10, no. 2 (June 1, 1980): 106-18. doi:10.1111/j.1943-278X.1980.tb00770.x.

Preti, Antonio. "School Shooting as a Culturally Enforced Way of Expressing Suicidal Hostile Intentions." Journal of the American Academy of Psychiatry and the Law Online 36, no. 4 (December 1, 2008): 544-50.

Przekop, Mary. "One More Battleground: Domestic Violence, Child Custody, and the Batterers' Relentless Pursuit of Their Victims through the Courts."Seattle J. Soc. Just. 9 (2010): 1053.

Raissian, Kerri M. "Hold Your Fire: Did the 1996 Federal Gun Control Act Expansion Reduce Domestic Homicides?" Journal of Policy Analysis and Management 35, no. 1 (January 1, 2016): 67-93. doi:10.1002/pam.21857.

Richardson, Erin G., and David Hemenway. "Homicide, Suicide, and Unintentional Firearm Fatality: Comparing the United States With Other High-Income Countries, 2003:" The Journal of Trauma: Injury, Infection, and Critical Care 70, no. 1 (January 2011): 238-43. doi:10.1097/TA.0b013e3181dbaddf.

Rocque, Michael. "Exploring School Rampage Shootings: Research, Theory, and Policy." The Social Science Journal 49, no. 3 (September 2012): 304-13. doi:10.1016/j.soscij.2011.11.001.

Rosenbaum, Milton. "The Role of Depression in Couples Involved in Murder-Suicide and Homicide." The American Journal of Psychiatry 147, no. 8 (August 1990): 1036-39.

Rosenberg, Jessica. "Mass Shootings and Mental Health Policy." Journal of Sociology and Social Welfare 41 (2014): 107.

Rosenfeld, Richard, Timothy M. Bray, and Arlen Egley. "Facilitating Violence: A Comparison of GangMotivated, Gang-Affiliated, and Nongang Youth Homicides: [1].” Journal of Quantitative Criminology 15, no. 4 (December 1999): 495-516. doi:http://dx.doi.org.proxy.lib.duke.edu/10.1023/A:1007548309620.

Saleva, Outi, Hanna Putkonen, Olli Kiviruusu, and Jouko Lönnqvist. "Homicide-suicide-An Event Hard to Prevent and Separate from Homicide or Suicide." Forensic Science International 166, no. 2-3 (March 2, 2007): 204-8. doi:10.1016/j.forsciint.2006.05.032. 
Sbraccia, Steve, and WNCN News. "Wife in Johnston Co. Murder-Suicide Was 'nervous' about Husband's Behavior, Documents Show.” WNCN, November 24, 2015.

http://wncn.com/2015/11/24/authorities-release-ids-of-husband-wife-in-johnston-co-murdersuicide/.

Sanford, C., S. W. Marshall, S. L. Martin, T. Coyne-Beasley, A. E. Waller, P. J. Cook, T. Norwood, and Z. Demissie. "Deaths from Violence in North Carolina, 2004: How Deaths Differ in Females and Males.” Injury Prevention 12, no. suppl 2 (December 1, 2006): ii10-16. doi:10.1136/ip.2006.012617.

Sen, Bisakha, and Anantachai Panjamapirom. "State Background Checks for Gun Purchase and Firearm Deaths: An Exploratory Study.” Preventive Medicine 55, no. 4 (October 2012): 346-50. doi:10.1016/j.ypmed.2012.07.019.

Siegel, Michael, Craig S. Ross, and Charles King. "The Relationship Between Gun Ownership and Firearm Homicide Rates in the United States, 1981-2010." American Journal of Public Health 103, no. 11 (November 2013): 2098-2105.

Simon, Thomas R., and Alex E. Crosby. "Suicide Planning among High School Students Who Report Attempting Suicide." Suicide \& Life - Threatening Behavior 30, no. 3 (Fall 2000): 213-21.

Starzomski, Andrew, and David Nussbaum. "The Self and the Psychology of Domestic HomicideSuicide." International Journal of Offender Therapy and Comparative Criminology 44, no. 4 (August 1, 2000): 468-79. doi:10.1177/0306624X00444005.

Swanson, Jeffrey W., and Alan R. Felthous. "Guns, Mental Illness, and the Law: Introduction to This Issue." Behavioral Sciences \& the Law 33, no. 2-3 (June 1, 2015): 167-77. doi:10.1002/bsl.2178.

Swanson, Jeffrey W., Nancy A. Sampson, Maria V. Petukhova, Alan M. Zaslavsky, Paul S. Appelbaum, Marvin S. Swartz, and Ronald C. Kessler. "Guns, Impulsive Angry Behavior, and Mental Disorders: Results from the National Comorbidity Survey Replication (NCS-R)." Behavioral Sciences \& the Law 33, no. 2-3 (June 1, 2015): 199-212. doi:10.1002/bsl.2172.

Swanson, Jeffrey W., Alison Gilbert Robertson, Linda K. Frisman, Michael A. Norko, Hsiu-Ju Lin, Marvin S. Swartz, and Philip J. Cook, in Reducing Gun Violence in America: Informing Policy with Evidence and Analysis (eds. Daniel W. Webster and Jon S. Vernick). JHU Press, 2013.

Verlinden, Stephanie, Michel Hersen, and Jay Thomas. "Risk Factors in School Shootings." Clinical Psychology Review 20, no. 1 (January 2000): 3-56. doi:10.1016/S0272-7358(99)00055-0.

Vigdor, Elizabeth Richardson, and James A. Mercy. "Do laws restricting access to firearms by domestic violence offenders prevent intimate partner homicide?" Evaluation Review 30.3 (2006): 313-346.

Vittes, Katherine A., Daniel W. Webster, Shannon Frattaroli, Barbara E. Claire, and Garen J. Wintemute. "Removing Guns From Batterers Findings From a Pilot Survey of Domestic Violence Restraining Order Recipients in California." Violence Against Women 19, no. 5 (May 1, 2013): 602-16. doi:10.1177/1077801213490561.

Sbraccia, Steve, and WNCN News. "Wife in Johnston Co. Murder-Suicide Was 'nervous' about Husband's Behavior, Documents Show." WNCN, November 24, 2015. http://wncn.com/2015/11/24/authorities-release-ids-of-husband-wife-in-johnston-co-murdersuicide/.

Webster, Daniel W., and Jon S. Vernick. Reducing Gun Violence in America: Informing Policy with Evidence and Analysis. JHU Press, 2013.

Wintemute, Garen J., Shannon Frattaroli, Barbara E. Claire, Katherine A. Vittes, and Daniel W. Webster. "Identifying Armed Respondents to Domestic Violence Restraining Orders and Recovering Their Firearms: Process Evaluation of an Initiative in California." American Journal of Public Health 104, no. 2 (February 2014): E113-18.

Zeoli, April M., and Shannon Frattaroli. "Evidence for optimism: Policies to limit batterers' access to guns." in Reducing Gun Violence in America: Informing Policy with Evidence and Analysis (eds. Daniel W. Webster and Jon S. Vernick). JHU Press, 2013:53-63. 